\author{
Military Technical College \\ Kobry El-Kobbah, \\ Cairo, Egypt
}

\section{$11^{\text {th }}$ International Conference on Civil and Architecture Engineering ICCAE-11-2016}

\title{
SOLID PARTS AND FENESTRATION IN BUILDING ENVELOPE ARE THEY WORKING IN SERIES OR IN PARALLEL UNDER CLIMATE CHANGE - STUDY IN EGYPT
}

\author{
Mohamed M. Mahdy ${ }^{1} \quad$ Mohammad Fahmy $^{1} \quad$ Ibrahim Elwy $^{1}$ \\ ${ }^{1-}$ Department of Architecture, Military Technical Collage, Cairo, Egypt.
}

\begin{abstract}
:
This paper presents a comprehensive evaluation for the results of a recent research effort concerning thermal comfort in residential buildings in Egypt. Thereby, the energy performance and thermal comfort were considered based on the instructions of the Egyptian Residential Energy Code to improve the efficiency of energy use. The conclusions of the aforementioned research on the building envelope (walls / fenestration) were tested together to make sure that the use of what seems to be the best solutions for external walls (solid part) in addition to the best solutions for fenestration (openings), will results in a better overall performance in energy consumption and thermal comfort, than implementing one of the two choices without the other. To attain that, two HVAC case study buildings were dynamically simulated in three dominant Egyptian climatic zones, using current climate conditions (2002) in addition to three other morphed climate change scenarios (2020, 2050 and 2080). Achieving the required rates for thermal comfort, as well as acquiring long term financial gains, both were the basic elements of evaluation. The results provide what seems to be a functionally and financially successful combination to fulfil the evaluation elements.
\end{abstract}

Keywords: Energy performance, Thermal comfort, climate change, Insulation, Fenestration.

\section{Introduction}

\subsection{Background}

The building envelope (skin) consists of structural materials and finishes that enclose space, separating the outdoor environment from indoor space. This includes walls, roofs, windows, doors, openings and floor surfaces [1]. As the building envelope controls the flow of heat between outdoor and indoor environments, a good envelope design plays a major role in determining the amount of energy a building will use in its operation [2], and can show optimization between natural lighting and thermal performance through passive solar techniques $[3,4]$. The effect of building envelope depends on the selection of its consisting materials, including the use of new thermal insulation materials to increases the thermal resistance of the external walls and ceilings, and the selection of appropriate fenestration (window wall ratio, glazing type) with applying the needed vertical and horizontal shading devices [1, 5].

Good external walls and ceiling insulation, are the first step to improve the indoor thermal behaviour and reduce the energy consumption, as about $8 \%$ of energy used in buildings wasted through the external walls, and about $6 \%$ wasted through the ceilings [3]. Due to the nature of the hot arid climate zone in which Egypt is located, external walls with large thickness were always been preferred in the vernacular architecture as a passive technique to reduce the heat and 
delay its transfer from the harsh external conditions [6]. Although the impact of this technique on improving the thermal performance of residential buildings particularly in hot arid zones, however people are no longer using it [5] due to financial issues and to save the indoor area. At present, the most widely used external walls for residential sector is the half red-brick $(12 \mathrm{~cm}$ thickness). The reason behind that is its relatively small initial cost compared with other external walls specifications. This ignores the negative impact of the half red-brick wall on indoor thermal comfort, energy consumption and associated running costs.

Among building envelope elements, the openings considered the main source of heat penetrating inside the building, as shown in Figure 1 (penetrating varies by the type of glass and by its specifications as transparency and purity grade) [6-8], as responsible for about $20 \%$ of energy used in buildings by increasing the heat load of the building, thus air-conditioning loads [3].

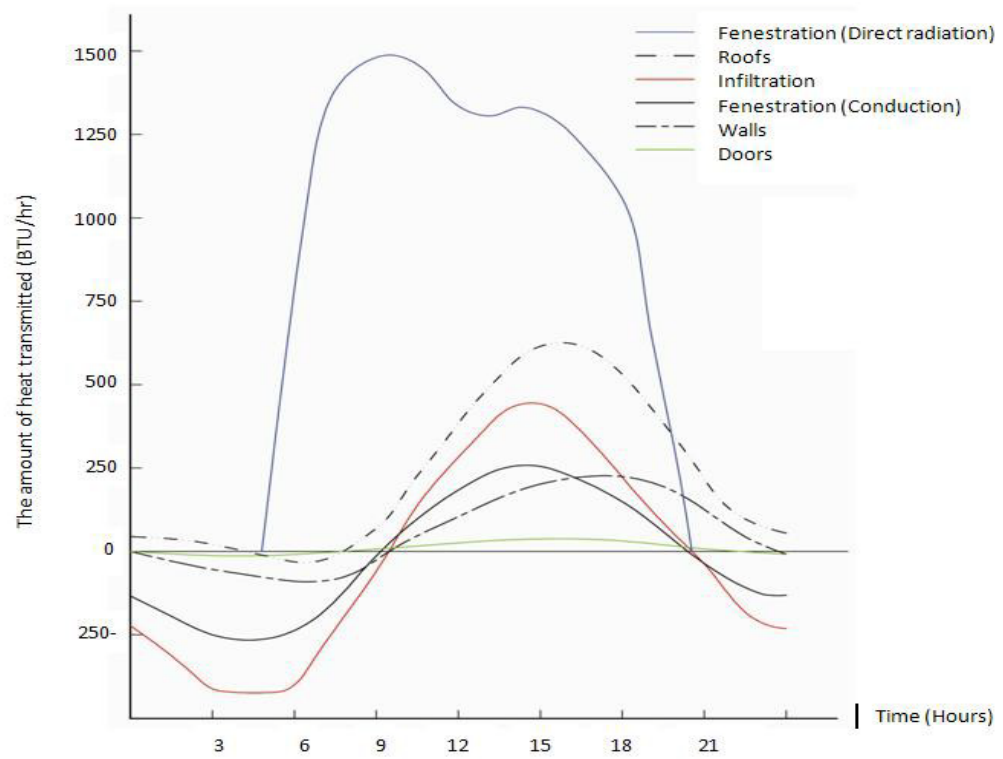

Figure1: The difference in the rate of heat permeability through various building envelope components [6, 9]

Therefore, the most effective way to reduce the solar load on the openings is to intercept direct solar radiation before it reaches the glass $[8,10]$ to control the indoor temperature, improve thermal comfort and reduce cooling loads [11-13] as fully shaded openings during hot weather can reduce solar heat gain by as much as $80 \%[1,10,11]$. Considerable amount of literature has been published regarding the importance of the shading techniques in different regions, some with the same climatic conditions as Egypt. A reduction of $1.5^{\circ} \mathrm{C}$ was achieved using vertical fins and combined shading devices, while Ahmed and Tarek [14] searching the impact of different shading devices on the thermal performance in residential buildings in Egypt. Ahmed [5] concluded that, vertical louvers with a prominence of $38 \mathrm{~cm}$ or more result in a decrease of $2^{\circ} \mathrm{C}$ in indoor temperature for all the four orientation, when he was investigating the effect of vertical louvers' length on the thermal performance of residential buildings in Egypt. Another study [15] showed that power consumption from air conditioning is reduced by an average of $25 \%$ if external shading is properly installed.

Selecting building materials have a great impact on the performance of the building, and the cost analysis over the building's life span is very important to determine the relative value of the use of specific material rather than the other products [6]. According to this, external walls and fenestration were our recent research focus among the elements of the building envelope 
components.

Previous research [16] was concerned with studying the effect of using different material specifications for the external walls on the cost of energy consumption (running cost) for achieving internal thermal comfort in Egypt. Four different types of external walls, in two different sets of cooling (natural ventilation and mechanical means) were tested through dynamic thermal simulations. The running cost in turn was compared to initial construction cost for each type of the used external walls. The results supported the use of the Egyptian Code for Improving the Efficiency of Energy Use in Buildings - Part 1: Residential Buildings (for simplicity it will be referred to as EREC for Egyptian Residential Energy Code) [17] recommendations to achieve indoor thermal comfort with minimum energy consumption (consequently minimum $\mathrm{CO}_{2}$ emissions) and the minimum running cost as well. More accurate studies and simulations were conducted [18] to extend the previous research, by evaluating the effect of external walls with different specifications on the project's initial cost and running cost for achieving internal thermal comfort in the present time and under climate change. Three different climatic zones in Egypt, as well as three current (2002) and predicted (2020 and 2050) weather data files were used by Building Performance Simulation software (BPS) [19] to evaluate four different external wall specifications. The energy analysis suggests different types of external walls according to location to optimise for thermal comfort and financial benefits.

The study has extended in other direction (the fenestration) [20], and investigates the effect of climate change on shading strategies that recommended by EREC. An HVAC case study building is dynamically simulated in three Egyptian climatic zones, using current climate condition (2002) in addition to three other morphed climate change scenarios (2020, 2050 and 2080). Then a comparison was held in the four different periods with and without the EREC's recommended shading parameters. The results show a minor effect for the future climate change on the efficiency of the current shading strategies that are approved and recommended by EREC, which confirms the effectiveness of using the existing shading specifications in future climatic conditions. The results were encouraging to develop a new research [21], to investigate the effect of the climate change on the choice of the fenestration properties -Window to Wall Ratio (WWR) and glass thermal properties- and its associated shading devices (as recommended by EREC) in order to optimize the energy consumption, as well as the long-term financial aspect of the building project, by running dynamic thermal simulations at three different climatic zones in Egypt, for four weather data files. In addition to the 112 simulations that have been carried out in this research, a computerized shading calculation tool [21], based on EREC's recommendations has been developed to find the best recommendations for the different variable combinations in the three major climatic zones in Egypt. In essence, all the different thermal properties (listed in EREC) of the various construction elements have been stored in a SQL Server database. In addition, all the required shading settings have been stored as well, with respects to different specifications, such as climatic zone, orientation, etc. For a given experiment parameter settings, a C\# program is responsible for taking these parameter values as an input arguments, then queries the database with these parameters to obtains the shading specification needed (if any).

The analysis of the simulations resulted in identifying different window wall ratios, glass types and shading device's associated prominence factors according to each climatic zone, to provide what seems to be the optimal combination for thermal comfort and financial benefits.

\subsection{Main purpose}

It was a prevailing assumption in the past that the climate does not change, meaning that the 
building which was designed to provide thermal comfort at the time of its establishment is supposed to continue the same level of thermal performance in the future until the end of its useful life. This assumption is no longer valid as evidenced by the reports of the International Panel on Climate Change [22]. The hours of sunshine and the proportion of direct radiation to diffused radiation are projected to increase in the future, while the modelling studies demonstrate a steady increase in cooling capacity and associated energy consumption required [23].

Therefore, the need to minimize overheating will become an increasing factor in design. Hence, simulate the performance of buildings under future climatic conditions has become of great importance, to provide an indication of the future thermal behaviour of the building and its ability to provide acceptable thermal conditions, probably with some modifications during their service life [23]. Therefore, the prediction and evaluation of the thermal behaviour for the residential buildings under future climate change scenarios, was the main focus of our recent research, via studying two of the main components of the building envelope: External walls and Fenestration. Some questions were raised: What will be the consequences of using the findings of the external walls research [18] (what seems to be the best combinations for external walls), in addition to what resulted from the fenestration research [21] (seemingly the best results we got for fenestration) with one another? Are the new outcomes will be better than the results that emerged from using each one of them separately in terms of the overall performance in energy consumption and thermal comfort? Conceptually the merge will give better results. However, is this assumption will remain immovable while introducing the long term financial studies? The main objective of the present study is to answer these questions.

\section{Approach (General Specifications for Simulation)}

As a computerized dynamic building thermal performance simulation tool "Energy plus", and its architectural friendly interface "DesignBuilder" takes into account all the principal heat-transfer theories that have a direct influence on energy consumption and indoor thermal comfort, such as transmitted solar radiation, air ventilation, convection heat transfer coefficient, etc.. In order to achieve the objective, DesignBuilder (DB) in its third version (V.3.0.0.105) [19] was used to investigate the effect of using three different sets of building materials: (1) Ordinary external wall materials in combined with the selected fenestration resulted from the aforementioned papers (OS), (2) Selected external wall materials with ordinary fenestration parameters (SO), finally (3) Selected external wall materials with selected fenestration (SS). The fourth probability: Ordinary external wall materials with ordinary fenestration parameters (OO) was excluded, as it was tested in previous studies $[16,18]$ and never achieve satisfactory outcomes. The effect of the three selected sets will be tested on two stereotypes residential buildings in Egypt with mechanical air conditioning (HVAC) installed. The thermal performance simulations will take place in three climatic zones defined in EREC [17]. These include Cairo and Delta, the North coast, and the Southern climatic zone. These simulations ran under the current climate conditions (2002), and under different climate change scenarios of three periods: 2020, 2050 and 2080. The simulations will produce two different parameters to help us to clarify our objective: Monthly Energy Consumption $(\mathrm{kWh})$ and Indoor Air Temperature $\left({ }^{\circ} \mathrm{C}\right)$.

\subsection{Climatic Zones}

Egypt is a large country with an area of approximately $1,000,000 \mathrm{~km}^{2}$, located between $22^{\circ} \mathrm{N}$ $31^{\circ} 37^{\prime} \mathrm{N}$ latitude and $24^{\circ} 57^{\prime} \mathrm{E}-35^{\circ} 45^{\prime} \mathrm{E}$ longitude. Egypt possesses a diversity of climate conditions ranging from extremely hot conditions in the desert regions such as the Western Desert, to cold conditions in Mountain St. Catherine in Sinai Peninsula [24]. However the overall climate of Egypt is characterized by the hot arid climate (Köppen classification: BWh) with very 
high solar radiation intensity most of the year [25, 26]. Egypt is divided into eight climatic zones: Northern Coast zone, Cairo and Delta zone, Northern Upper Egypt zone, Southern Upper Egypt zone, East Coast zone, Highland's zone, Desert zone and Southern Egypt zone.

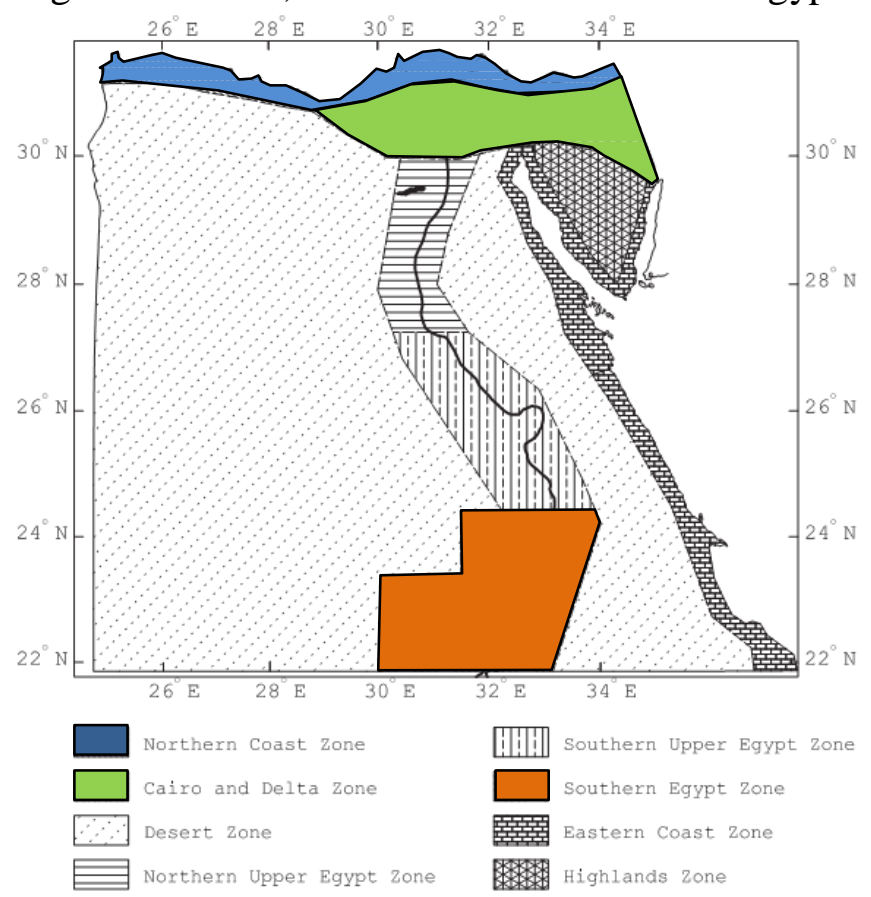

Figure 2: Egypt's climatic zones classificationmap according to EREC[17, 24].

The paper will focus on the main three climatic zones (shown in Figure 2) defined in EREC [17]. These three climatic zones are: (1) Cairo and Delta zone (Cairo governorate), (2) North coast zone (Alexandria governorate) and (3) the Southern Egypt zone (Aswan governorate). About $50 \%$ of the construction projects carried out in Egypt are located in Cairo and Alexandria governorates [27], while Aswan governorate is considered a very different zone in terms of the climatic aspects compared to the other zones $[6,17,28]$.

\subsection{Thermal Comfort Zone}

Previous research underpins the theory of Adaptive Comfort [29, 30]. It has shown that people can adapt and can be comfortable at higher temperatures than those conventionally adopted. As mentioned by Givoni [31], people who lives and acclimatized to prevailing hot environment regions, would prefer higher temperature. Accordingly, the thermal comfort zone $\left(20^{\circ} \mathrm{C}-29^{\circ} \mathrm{C}\right)$ was used in the simulations. This is an modification of the original comfort zone $\left(22.2^{\circ} \mathrm{C}-\right.$ $25.6^{\circ} \mathrm{C}$ ) mentioned in EREC [17]. The modification has been applied using Givoni approach [31] through the inclusion of both mean values of the slightly hot zone $\left(25.6^{\circ} \mathrm{C}-34.5^{\circ} \mathrm{C}\right)$ and of the slightly cold zone $\left(22.2^{\circ} \mathrm{C}-17.5^{\circ} \mathrm{C}\right)$ to form the new modified thermal comfort zone $\left(20^{\circ} \mathrm{C}-29^{\circ} \mathrm{C}\right)$. As we are working with the assumption that higher air temperatures are tolerated in this climatic context, we have not used PMV at all. We are only using air temperature as the indication. 


\subsection{Model Definition}

Two different residential buildings (governmental Housing / low-income housing) were used in the simulations ${ }^{1}$ :

\subsubsection{Building $1(B-1)$}

The building consists of five floors with total height of $15 \mathrm{~m}$, where each floor has four residential flats with an approximate area of $85 \mathrm{~m}^{2}$ each. The average number of occupants per flat is four (See Figures 3 and 4).

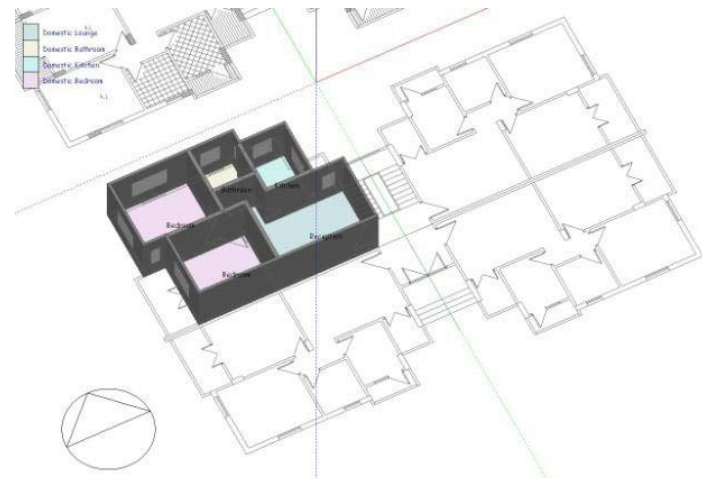

Figure 3: Typical plan for the Modeled flat.

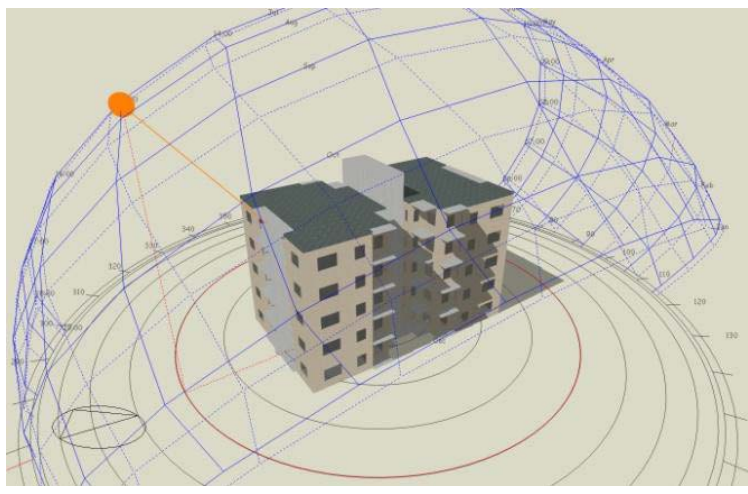

Figure 4: Solar analysis of the model in Alexandria.

\subsubsection{Building $2(B-2)$}

The building consists of six floors with total height of $18 \mathrm{~m}$. Each floor consists of four residential flats with an area of $86 \mathrm{~m}^{2}$ per flat and four persons average number of occupants. The building outline contains many corners which casting self shading, and it can be noticed that there is no openings on the East and West façades. The building floor plan is shown in Figure 5, and the building model is shown in Figure 6.

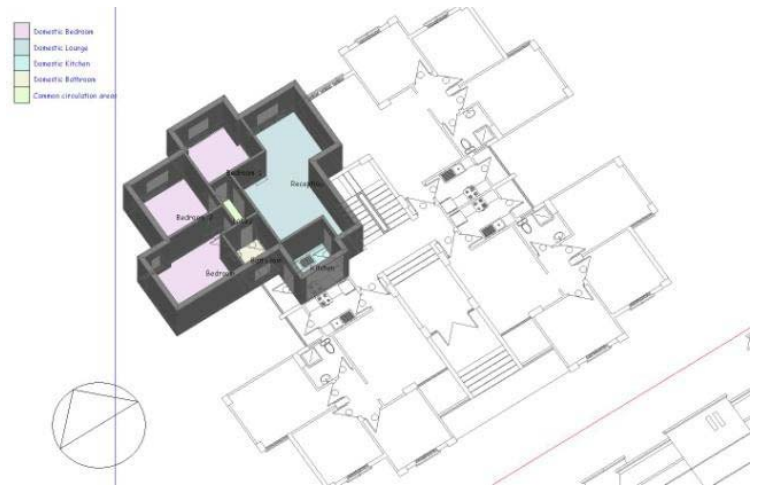

Figure 5: Typical plan for the Modeled flat.

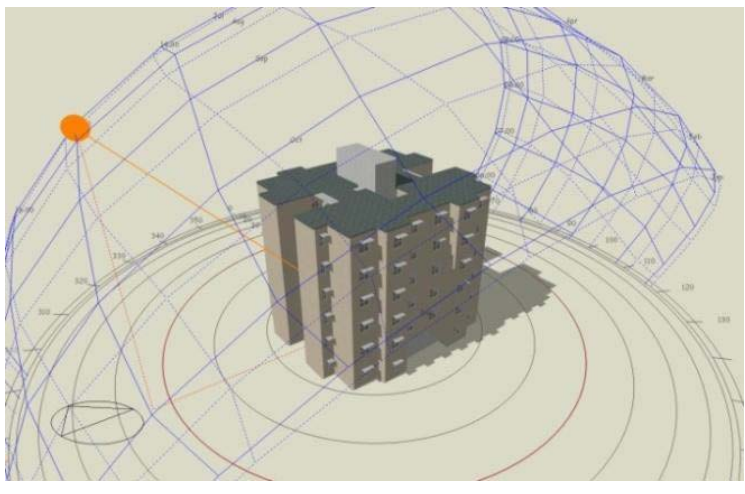

Figure 6: Solar analysis of the model used in Aswan.

\subsection{Simulation sets}

The effect of three different sets of building materials will be tested on the aforementioned two residential buildings:

\footnotetext{
${ }^{1} \mathrm{NB}$ : After finishing the simulations and in order to perform another research, two other prototypes were subjected to the same simulation process. The results were of the same indications, even though it does not presented here.
} 
- Ordinary external wall materials in combined with the selected fenestration (OS).

- Selected external wall materials with Ordinary fenestration parameters (SO).

- Selected external wall materials with selected fenestration (SS).

The ordinary materials (O) are the most commonly used materials in Egypt, most probably due to their low price. While the selected materials (S) were obtained as results of the previous research $[18,21]$ via numerous tests for the most commonly used materials in Egypt and the recommended materials by EREC (Whether building materials for external walls or the various types of glass available in the Egyptian market), nevertheless it's not necessarily the cheapest in the initial cost, but seemingly provides the optimal solution for thermal comfort and financial gains on the long term. Table 1 clarify the different materials for each (O and $\mathrm{S}$ ) category, used in the simulations for the different climatic zones.

Table 1: General description of the materials used in the simulations.

\begin{tabular}{|c|c|c|c|c|}
\hline Category & $\begin{array}{l}\text { Building } \\
\text { Envelope }\end{array}$ & Alexandria & Cairo & Aswan \\
\hline \multirow{2}{*}{$\begin{array}{l}\text { Ordinary } \\
\text { (O) }\end{array}$} & External Walls & Half red-brick wall $(12 \mathrm{~cm})$ & Half red-brick wall $(12 \mathrm{~cm})$ & Half red-brick wall $(12 \mathrm{~cm})$ \\
\hline & Fenestration & Single clear 6.4mm (G1) & Single clear $6.4 \mathrm{~mm}$ (G1) & Single clear $6.4 \mathrm{~mm}(\mathrm{G} 1)$ \\
\hline \multirow{2}{*}{$\begin{array}{l}\text { Selected } \\
\quad \text { (S) }\end{array}$} & External Walls & $\begin{array}{c}\text { Double wall of half red- } \\
\text { brick-air gap (Dair) }\end{array}$ & $\begin{array}{c}\text { Double wall of half red- } \\
\text { brick-air gap (Dair) }\end{array}$ & $\begin{array}{c}\text { Double wall of half red- } \\
\text { brick-insulation(Dins) }\end{array}$ \\
\hline & Fenestration & $\begin{array}{c}\text { Single clear Reflective } \\
6.4 \mathrm{~mm}(\mathrm{G} 2)+20 \% \mathrm{WWR}\end{array}$ & $\begin{array}{c}\text { Single clear Reflective } \\
6.4 \mathrm{~mm}(\mathrm{G} 2)+20 \% \mathrm{WWR}\end{array}$ & $\begin{array}{c}\text { Single clear Reflective } \\
6.4 \mathrm{~mm}(\mathrm{G} 2)+20 \% \mathrm{WWR}\end{array}$ \\
\hline
\end{tabular}

Detailed specifications for each material will be mentioned in the following:

\subsubsection{External Wall Specifications}

The specifications for external wall constructions used are presented in Table 2. The thermal properties for the construction materials were obtained from EREC [17], and from the Egyptian Specifications for Thermal Insulation Work Items [32].

Appropriate materials were used for the construction in the different three climatic zones, evaluated in previous simulations [33], which recommended the use of the double wall of half red-brick with $5 \mathrm{~cm}$ of internal expanded polystyrene thermal insulation layer (Dins) wall as the optimum external wall in Aswan, and the use of the double wall of half red-brick with $5 \mathrm{~cm}$ air gap in between (Dair) wall for Alexandria and Cairo. These are the optimum specifications shown to achieve indoor thermal comfort, minimize the energy consumption, while attaining the maximum financial. While the regular half red-brick wall which is the most commonly used for construction in Egypt in spite of its negative impact on the indoor thermal comfort, energy consumption and associated running costs (See Figure 7). 
Table 2: External Walls main characteristics.

\begin{tabular}{|l|c|c|c|}
\hline \multicolumn{1}{|c|}{ External Walls } & ABBRV. & $\begin{array}{c}\text { Thick. } \\
(\mathbf{m m})\end{array}$ & $\begin{array}{c}\text { U-Value } \\
\left(\mathbf{W} / \mathbf{m}^{2} \mathbf{K}\right)\end{array}$ \\
\hline Half red-brick wall. & $12 \mathrm{~cm}$ & 12 & 2.519 \\
\hline Double wall of half red-brick with 5 cm air gap in between. & Dair & 29 & 1.463 \\
\hline $\begin{array}{l}\text { Double wall of half red-brick with additional internal 5cm of } \\
\text { expanded polystyrene thermal insulation layer. }\end{array}$ & Dins & 29 & 0.503 \\
\hline
\end{tabular}

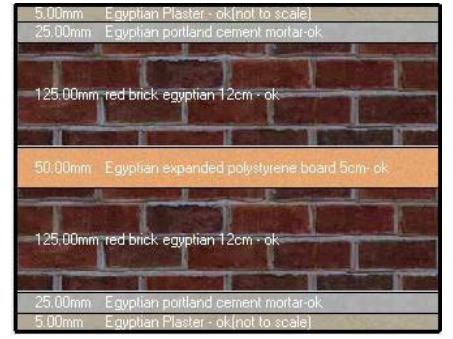

Dins

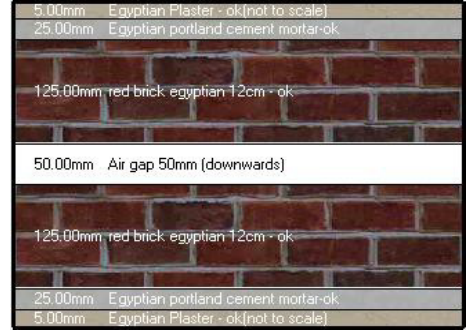

Dair

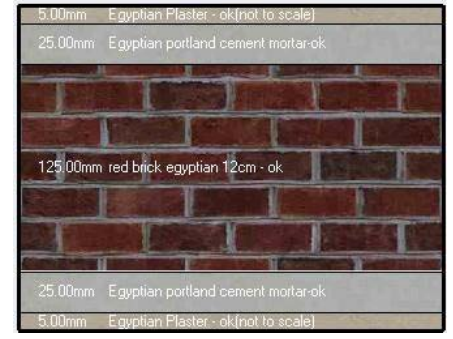

$12 \mathrm{~cm}$

Figure 7: Wall sections used.

\subsubsection{Glass Specifications}

There are four main glass categories commonly used in Egypt, mentioned and specified in EREC [17]: (1) Single glass. (2) Single Reflective glass. (3) Double glass. (4) Double Reflective glass. As recent results recommend [21], the Single Clear Reflective $6.4 \mathrm{~mm}$, with $8 \%$ Stainless-Steel Cover was used in the simulations as the most cost-effective glass type to be used on the long run. While the Clear $6.4 \mathrm{~mm}$ glass was used as the regular glass type which is the most commonly used for construction in Egypt (See Table 3).

Table 3: Used glass specifications.

\begin{tabular}{|l|l|l|c|c|c|}
\hline \multicolumn{1}{|c|}{ Name } & \multicolumn{1}{|c|}{ Category } & SHGC $^{*}$ & LT $^{* *}$ & $\begin{array}{c}\text { U-Value } \\
\left(\mathrm{W} / \mathrm{m}^{2} \mathrm{~K}\right)\end{array}$ \\
\hline G1 & Clear 6.4mm & Single & 0.71 & 0.65 & 5.76 \\
\hline G2 & Clear Reflective 6.4mm - (Stainless steel Cover 8\%) & Single Reflective & 0.18 & 0.06 & 5.36 \\
\hline
\end{tabular}

SHGC: Solar Heat Gain Coefficient.

LT: Light Transmission.

\subsection{Weather Data Files (WDF)}

Four different weather data files: 2002, 2020, 2050 and 2080 were used in the simulations, to provide the most comprehensive simulation period available to test our hypothesis, starting from the current weather conditions (2002), then the predicted weather data files (2020, 2050 and 2080). The current weather data file (2002) was obtained from the official site of the U.S Department of Energy [34]. By using the Climate Change World Weather File Generator (CCWorldWeatherGen) [35], the future weather data files for 2020, 2050 and 2080 were generated, for the climatic zones that has been tested in Egypt, and they cover the periods 20102039, 2040-2069 and 2070-2099 respectively [36]. The new weather data files have been used accordingly for the simulations, after using the DB weather data converter tool to convert them into an hourly weather data files that can be used in DB. The available weather data files gave us a maximum test period of 88 years, as the beginning of 2012 was assumed to be the starting construction year; the WDFs were divided as follows: 
- 2002 weather data file (cover the period of 14 years): from 2012 to 2025.

- 2020 weather data file (cover the period of 14 years): from 2026 to 2039.

- 2050 weather data file (cover the period of 30 years): from 2040 to 2069.

- 2080 weather data file (cover the period of 30 years): from 2070 to 2099.

CCWorldWeatherGen [35], is a Microsoft Excel based tool, generating climate change weather data files, which can be used in BPS programs by transforming current Energy Plus Weather files (EPW) into climate change EPW files that are compatible with the majority of BPS programs [37]. The following figure (Fig. 8) shows the predicted scenarios for the future climate change, from the present to the 2080 projections in the three climatic zones (Alexandria, Cairo and Aswan respectively) in Egypt. The left graphs presents the outside temperatures for the current and the three future scenarios, while the graphs on the right shows the direct solar radiations for the same climatic periods. As noticed, the temperature increases by moving from a climatic period to another with a clear difference in all of the three tested climatic zones. While the solar radiation graphs did not show the same rates of change at any of the different zones, on the contrary the solar radiation rates were very close to the existing conditions..
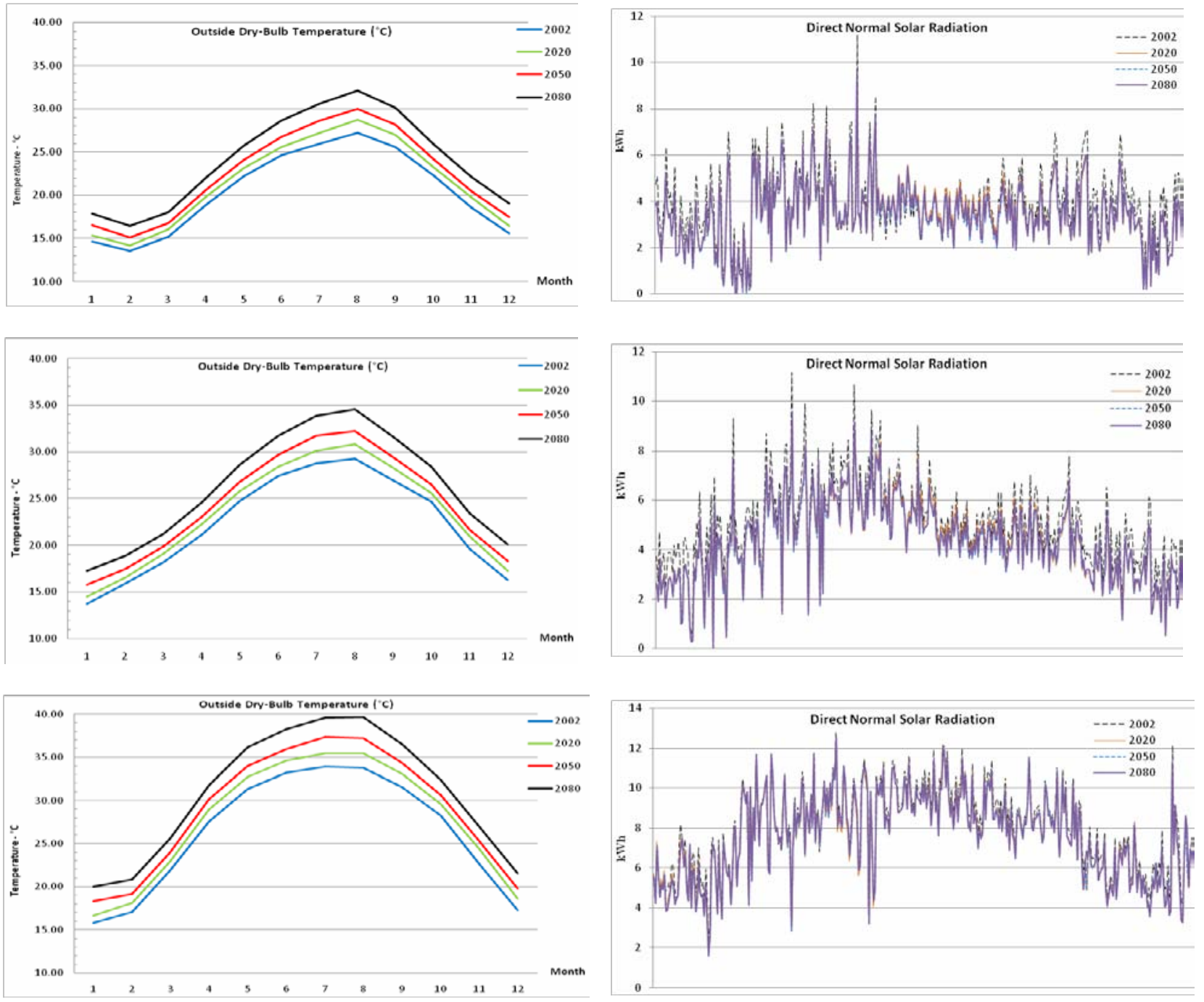

Figure 8: Future weather projections for Alexandria, Cairo and Aswan. 


\subsection{Activities and HVAC Systems}

Schedules were used (in conjunction with the cooling and heating setpoints) to control the timing in DesignBuilder and to define certain activities in the simulations, such as occupancy times, equipment, lighting and HVAC operation [38]. Fixed energy consumption schedules were used for the simulations, and has been defined via fixed activity template based on the common lifestyle for the residents of Egypt (holidays, work hours, etc.) [39]. For each combination of parameters that have been tested, a simulation has been conducted to evaluate thermal comfort and to obtain the total energy consumption in $\mathrm{kWh}$ from room electricity (house appliances, etc.), lighting and the HVAC systems.

Hybrid systems (mixed mode of HVAC systems and natural ventilation) were used to benefit from passive cooling when available and make efficient use of mechanical cooling systems during extreme periods. Simple HVAC systems setup were used in the simulations, where the heating and cooling systems are modelled using basic loads calculation algorithm (Energy Plus zone HVAC ideal loads) [38], in order to supply hot or cold air to meet the heating or cooling loads according to the required setpoints. The HVAC specifications include the use of split airconditioning units (with cooling COP $=1.83$ ) that are generally used for domestic purposes in Egypt for the whole day in the summer when the temperature exceeds $29^{\circ} \mathrm{C}$ until it drops below $25^{\circ} \mathrm{C}$; otherwise, natural ventilation was used.

The HVAC systems were used in this experiments as according to [29] it is possible to design buildings to provide thermal comfort for the occupants while operate in free mode, when the prevailing mean outdoor temperature lies within the range $10-30^{\circ} \mathrm{C}$, which did not applied to our cases especially during the summer hot period. And according to previous study [40] natural ventilation were not sufficient to achieve thermal comfort individually in the summer period; under the same experiment conditions in Cairo with different external wall specifications. It should be noted that, in the cases where the internal temperature rises beyond the thermal comfort zone, comfort still can be obtained using higher HVAC units of higher cooling capacity (by changing the required setpoints), which increases the overall energy consumption. However, in this paper the HVAC equipments (i.e. setpoints) were kept fixed in all the simulations.

The simulation techniques including modelling, building materials assignment, lighting and HVAC systems configurations have been examined in order to validate the simulated results. For validating the simulated results, the real time data on monthly energy consumption were collected using the electricity bills for the two different models (in Cairo climatic zone). By comparing the exact energy consumption with DB simulated results for each model, it is found that the accuracy reached almost $90 \%$ for one of the cases and about $87 \%$ for the other. This comparison demonstrates that the DB predictions are in good agreement with the on-site measured data, thus this simulation processes can be used to validate the research objectives in the current weather conditions, and under future climate change scenarios. 


\subsection{Prices of construction materials and energy}

\subsubsection{Construction Material Costs}

The price-list of Construction materials, derived from The Engineering Authority Indicative Guide [41], was used to calculate the initial cost of the different building materials in each case tested in the simulations.

\subsubsection{Electric Energy Prices}

For the financial analysis, the cost of the annual energy consumption per flat was calculated using the electricity tariff derived by the Egyptian Ministry of Electricity and Energy for the residential sector [42]. The different categories and prices are shown in Table 4.

Table 4: The electricity tariff.

\begin{tabular}{|c|c|c|c|c|c|}
\hline no. & Category $(\mathrm{kW})$ & Price (EGP) & no. & Category $(\mathrm{kW})$ & Price (EGP) \\
\hline 1 & 50 & 0.05 & 4 & $351-650$ & 0.24 \\
\hline 2 & $51-200$ & 0.11 & 5 & $651-1000$ & 0.39 \\
\hline 3 & $201-350$ & 0.16 & 6 & Over 1000 & 0.48 \\
\hline
\end{tabular}

\section{Results and Discussion}

\subsection{Simulation Results}

The results contain indicators for 72 simulations (for both buildings) that have been conducted through the research. The aforementioned results divided into three separate graphs: the monthly energy consumption ( $\mathrm{kWh}$ ), annual energy cost in Egyptian Pound (EGP), as well as the levels of thermal comfort compared to the outdoor and indoor temperatures $\left({ }^{\circ} \mathrm{C}\right)$. These measures were plotted for the three climatic zones (Alexandria, Cairo and Aswan) in Figures 9(a/b), 10(a/b) and 11(a/b) for B-1 building, and in Figures $12(\mathrm{a} / \mathrm{b}), 13(\mathrm{a} / \mathrm{b})$ and $14(\mathrm{a} / \mathrm{b})$ for $\mathrm{B}-2$ building respectively. Each graph divided into four different climatic periods that have been addressed in the study (2002, 2020, 2050 and 2080). The results analysis also includes a financial study of the construction cost (initial cost), and its relation to the cost of the energy consumption (running cost), from the perspective of long-term investment and the interest that would accrue to the investors in the real estate sector.

For each climatic period: (1) the upper left graph represents the monthly energy consumption for the three different sets of building materials (OS, SO and SS). As expected, the energy consumption increases when moving from a climatic period to the following one, as a result of the temperature increase under climate change [43] in all of the climatic zones. (2) The upper right graph represents the annual energy cost according to the household electricity tariffs used in Egypt [42]. As expected, the results show that the cost is directly proportional to the increase in energy consumption. (3) The lower graph presents the indoor and outdoor mean temperature variations for the whole year, with each number corresponding to the respective month, along with the thermal comfort zone. As expected, these vary for the different climate zones, weather periods and the different sets of building materials used. 


\subsection{Financial Analysis}

As a non professional financial study, some financial equations have been developed and derived based on the Net Present Value (NPV) financial model. The subsidised electricity tariff as well as the interest rate are assumed to be fixed over the study period. Putting into consideration that, the increase in the electricity tariffs (the removal of subsidies) or the decrease in the interest rate will reflect into more financial benefits in favour of the search hypothesis as tested in an ongoing research. The financial study idea simply summarized in finding the difference in the long term financial gains of 88 years period (see Section 2.5) between:

1) Those who preferred to invest what seems to be a small amount of money (at first glance) in the initial cost of the construction (refer to as $X$ ) and is thus chose to use the previous studies recommendations for only one of the building's envelope components, whether it's the external walls or the fenestration only (cases SO or OS). NB: in order to achieve indoor thermal comfort in case SO, additional external shading devices for fenestration will be used according to the requirements of the code. This additional cost will reflect sometimes on increasing the total cost as shown in Table 4.

2) Those who preferred to invest a larger amount of money in the initial cost of the building (refer to as $Y$ ) and is thus use the recommendations of the previous studies for both the external walls and fenestration together (case SS).

The aim is to point out the best cost effective set of the three different sets of building materials (OS, SO and SS) in each climatic zone, taking into account the total initial cost and the running cost for each set. The total initial cost as mentioned in Table 5 calculated by adding the initial cost of the external walls to the fenestration cost for each building (B-1 and B-2).

Table 5: Total initial cost of the simulated buildings (EGP).

\begin{tabular}{|c|c|c|c|c|c|}
\hline & & Climatic zone & Wall cost & Fenestration cost & Total \\
\hline \multirow{7}{*}{ 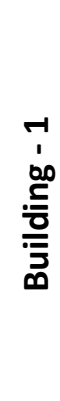 } & OS & All & 1528 & 3531 & 5059 \\
\hline & \multirow{3}{*}{ SO } & Alex & 3104 & 3858 & 6962 \\
\hline & & Cairo & 3104 & 4013 & 7117 \\
\hline & & Aswan & 5969 & 4064 & 10033 \\
\hline & \multirow{3}{*}{ SS } & Alex & 3104 & 3531 & 6635 \\
\hline & & Cairo & 3104 & 3531 & 6635 \\
\hline & & Aswan & 5969 & 3531 & 9500 \\
\hline \multirow{7}{*}{ 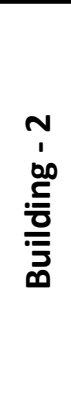 } & OS & All & 1832 & 3746 & 5578 \\
\hline & \multirow{3}{*}{ SO } & Alex & 3721 & 3595 & 7316 \\
\hline & & Cairo & 3721 & 3755 & 7476 \\
\hline & & Aswan & 7156 & 3755 & 10911 \\
\hline & \multirow{3}{*}{ SS } & Alex & 3721 & 3746 & 7467 \\
\hline & & Cairo & 3721 & 3746 & 7467 \\
\hline & & Aswan & 7156 & 3746 & 10902 \\
\hline
\end{tabular}


We assume that, investor $X$ used one of the sets SO or OS, while investor $Y$ used the SS set. For each building materials set, we calculate the initial cost paid by investor $X$ and $Y$ (Table 5). The difference between the initial costs for the different sets of building materials (SO,OS and SS) will be invested in a bank with the regular 9\% interest rate in Egypt [44], using the following formula:

Where:

The amount of money generated after $N$ years of investment.

The difference in initial costs in Egyptian pound (EGP).

$N \quad$ Number of Years of bank investment.

In addition, the bills paid for the consumed energy by each investor is referred to as the running cost, the difference in the running cost between the sets of building materials (savings in the annual energy bills in EGP) will be invested as well using the following equation:

Where:

The amount of money generated after $N$ years of investment.

The difference in running costs in Egyptian pound (EGP).

$N \quad$ Number of Years of bank investment.

In the financial study, the Case SS will be taken as the baseline as it achieved the lowest monthly energy consumption, thus the lowest annual cost for energy, as well as it achieved the best level of thermal comfort for the occupants of the architecture spaces in all the simulations. This includes the two buildings (B-1 and B-2) that have been studied, in the different three climatic regions (Alexandria, Cairo and Aswan), in all the climatic periods that have been studied (2002, 2020, 2050 and 2080).

The financial implications for the results of the simulations are summarised in Tables 6 and 7 for buildings B-1 and B-2 respectively. Each table demonstrate the financial analysis of the three climatic zones (Alexandria, Cairo and Aswan) sequentially. These tables show the running costs for the energy consumed in each zone for each climatic period used in our simulations (subtotal), and the average annual running cost obtained by dividing the running cost of the four climatic periods added together (overall) by 88 years, as well as the initial cost of each building material set (SO, OS and SS). Note that, in each of the results tables, the final total amount of saving ( shown in negative (and typed in red bold-face) indicates that its corresponding set of material is more cost effective than the baseline set (SS). 


\subsection{Discussion}

The analysis of the simulation results, along with the financial analysis both will be used in the following discussion, regarding each building (B-1 and B-2) in every climatic zone used in the simulations:

\subsubsection{Building-1}

1) Alexandria:

- The Case SS achieved the best energy performance (monthly energy consumption and annual cost), in addition to the best thermal performance in terms of thermal comfort.

- As noticed from the thermal comfort curves (Figures 9/a and 9/b) all the building specifications (OS, SO and SS) achieved the requirements of the thermal comfort in all the different climatic periods, in addition to the convergence levels of thermal performance for all the specifications especially in the middle of the hot period (July and August), which makes us resort to the financial studies that suggest the use of case OS, as the only case that overcomes the SS financially as shown in Table 6.

2) Cairo:

- The Case SS again achieved the best energy performance, as well as the best thermal performance in terms of thermal comfort.

- In spite of getting higher financial returns (see Table 6) compared to SS. the OS case will not be chosen as the best case for Cairo, as according to the thermal performance curves (Figures 10/a and 10/b) OS will be so close to the lack of thermal comfort in 2080 climatic period. So it seems that SS combination will be the only specification that achieves thermal comfort with financial gains.

3) Aswan:

- The Case SS likewise achieved the best energy performance, in addition to the best thermal performance as shown in Figures 11/a and 11/b and the best financial gains according to the financial study (See Table 6).

- The requirements to achieve the thermal comfort necessitate the use of the SS combination, where other specifications do not achieve even asymptotic level of thermal comfort of the SS specifications in all climatic periods, especially in the period of 2080, where they didn't meet the thermal comfort requirements in this period.

\subsubsection{Building-2}

1) Alexandria:

- The Case SS has achieved the best monthly energy consumption and annual energy cost, in addition to the best thermal performance.

- As shown in the thermal comfort curves in Figures 12/a and 12/b, all the building materials sets achieved the thermal comfort requirements in all the different climatic periods with very close levels of performance, which makes us resort to the financial studies that suggest the use of case OS, which was the only case that overcomes the SS financially as shown in Table 7. 
2) Cairo:

- The case SS, seems to achieve the best energy and thermal performance (Figures 13/a, and 13/b), as well as the best financial gains according to the financial study (Table 7).

\section{3) Aswan:}

- Case SS, achieved the best energy performance (monthly energy consumption and annual cost), in addition to the best thermal performance in terms of thermal comfort as shown in Figures 14/a, and 14/b. As well as the best financial gains (see Table 7).

\section{Conclusion:}

In this paper, the effect of the climate change on the various building material sets used for the external walls and fenestration (as parts of the building envelope) has been evaluated. In the simulations, three different sets of building materials have been tested, applied for two residential buildings, and simulated in three different Egyptian climatic zones. The experiments are based on building performance simulations that take into account the external walls materials, WWR, glass type, shading devices recommended by EREC for each climatic zone, and four weather data files representing the current and future weather scenarios, to evaluate the energy consumption and the thermal comfort of each of the building models. In addition, a financial analysis based on the results of the simulations has been performed to point out what seems to be the most cost-effective specification (of the three building material sets used) with respect to the initial and the running costs. The results showed that, in spite of the large area of the solid part in the building envelope, and the high cost needed for its treatment to mitigate the external harsh conditions. However, the openings effect in allowing the external heat to penetrate in the indoor space through solar radiation makes a big and obvious impact on the monthly energy consumption, hence annual energy cost.

Simulation results showed different performance for each building materials set across the climatic zones. However, in general, the results recommend the use of the half red-brick wall $(12 \mathrm{~cm})$ for the external walls and the Single clear Reflective $6.4 \mathrm{~mm}$ (G2) glass with 20\% WWR (OS set), as the most cost-effective combination to be used on the long run in Alexandria. The set SS was recommended to be used for Cairo and Aswan climatic zones, as the most costeffective set of building materials. In Cairo the SS set consists of the Double wall of half redbrick with $5 \mathrm{~cm}$ air gap (Dair) for the external walls, and the Single clear Reflective 6.4mm (G2) glass with 20\% WWR. While the SS set for Aswan consists of the Double wall of half red-brick with additional internal $5 \mathrm{~cm}$ of expanded polystyrene thermal insulation layer for the external walls, and the Single clear Reflective 6.4mm (G2) glass with 20\% WWR for fenestration.

\section{References}

1. Okba, E.M., Building envelope design as a passive cooling technique in Passive and Low Energy Cooling for the Built Environment. 2005: Santorini, Greece

2. USDoE, U.S.D.o.E.-. Energy Efficiency and Renewable Energy: Building Envelope. 2004 [cited; Available from:www.eere.energy.gov.

3. Makram, A.A.S., Sustainable Architecture As an Approach for Hospitals Design in Architecture. 2008 (Unpublished), Alexandria university: Alexandria. p. 253.

4. Kassim, A. and H. Bathis, Energy efficiency opportunities for government hospitals. 2003, report prepared under the Malaysian, Danish environmental cooperation program. 
5. Ahmed, A.A.E.-M.M.A., Using simulation for studying the influence of vertical shading devices on the thermal performance of residential buildings (Case study: New Assiut City). Ain Shams Engineering Journal, 2012. 3(2): p. 163-174.

6. Shafaq El-Wakeel, M.S., Climate and Tropical Architecture. 1989, Cairo: Alem Al Kutob. 324.

7. Datta, G., Effect of fixed horizontal louver shading devices on thermal performance of building by TRNSYS simulation. Renewable Energy, 2001. 23: p. 497-507.

8. Offiong, A. and A.U. Ukpoho, External window shading treatment effects on internal environmental temperature of buildings. Renewable Energy, 2004. 29(14): p. 2153-2165.

9. Khudari, H.A.W., The Impact of Form on Energy Savings - a Study of Hospital Buildings in Egypt, in Architecture. 2001 (Unpublished), Cairo University: Cairo.

10. Palmero-Marrero, A.I. and A.C. Oliveira, Effect of louver shading devices on building energy requirements. Applied Energy, 2010. 87(6): p. 2040-2049.

11. Al-Tamimi, N.A.F., Sharifah Fairuz Syed, The Potential of Shading Devices for Temperature Reduction in High-Rise Residential Buildings in the Tropics. Procedia Engineering, 2011. 21: p. 273-282.

12. Vincenzo Corrado, V.S., Andrea Vosilla, Performance analysis of external shading devices, in Plea2004 The 21th Conference on Passive and Low Energy Architecture. 2004: Eindhoven, The Netherlands.

13. Radhi, H., A. Eltrapolsi, and S. Sharples, Will energy regulations in the Gulf States make buildings more comfortable - A scoping study of residential buildings. Applied Energy, 2009. 86(12): p. 2531-2539.

14. Ahmed A. M. Ali, T.M.F.A., Evaluating the impact of shading devices on the indoor thermal comfort of residential buildings in Egypt, in IBPSA, SB 2012. 2012: Wisconsin, USA.

15. Yang, K.H. and R.L. Hwang, Energy conservation of buildings in Taiwan. Pattern Recognition, 1995. 28(10): p. 1483-1491.

16. Mahdy, M.M. and M. Nikolopoulou, From construction to operation: Achieving indoor thermal comfort via altering external walls specifications in Egypt in International Conference on Green Buildings Technologies and Materials (GBTM). 2012: China.

17. Centre, H.a.B.N.R., Egyptian Code for Improving the Efficiency of Energy Use in Buildings, Part 1: Residential Buildings (306/1). in ECP 305-2005 U.a.U.D.-E. Ministry of Housing, Editor. 2008: Cairo - Egypt.

18. Mahdy, M.M. and M. Nikolopoulou, The cost of achieving thermal comfort via altering external walls specifications in Egypt; from construction to operation through different climate change scenarios, in Building Simulation conference 2013: France.

19. DB, D.S.L.-. DesignBuilder software. Retrieved from: http://www.designbuilder.co.uk/". 2012: Stroud, UK.

20. Mahdy, M.M., M. Nikolopoulou, and M. Fahmy, Climate Change scenarios effects on residential buildings shading strategies in Egypt in Building Simulation Cairo 2013 - Towards Sustainable \& Green Built Environment. 2013: Cairo - Egypt.

21. Mahdy, M.M. and M. Nikolopoulou, Evaluation of fenestration specifications in Egypt in terms of energy consumption and long term cost-effectiveness. Energy and Buildings, 2014. 69(0): p. 329-343.

22. IPCC, I.P.o.C.C.-. Synthesis Report, fourth assessment report of climate change. Online at: http://www.ipcc.ch/publications_and_data/ar4/syr/en/contents.html.2007:Geneva, Switzerland.

23. Levermore, G.J., et al., Deriving and using future weather data for building design from UK climate change projections - an overview of the COPSE Project. 2012, Manchester University: Manchester, UK.

24. Mahmoud, A.H.A., An analysis of bioclimatic zones and implications for design of outdoor built environments in Egypt. Building and Environment, 2011. 46(3): p. 605-620.

25. SolarGIS, G.S.s.r.o.-. Global Horizontal Irradiation - Africa and Middle East. 2013 [cited; Available from: http://solargis.info/doc/_pics/freemaps/1000px/ghi/SolarGIS-Solar-map-Africa-and-Middle-East-en.png.

26. SODA, S.R.D.-- Maps of Irradiation - Africa - Photovoltaic Solar Electricity Potential. 2013 [cited; Available from: http://www.soda-is.com/eng/map/maps_for_free.html\#pvgis-africa.

27. Joe Huang, L.B., and others, The development of residential and commercial building energy standards for Egypt, in Energy conservation in buildings workshop 2003.

28. Gira, A.A.E.A., Evaluation of the Thermal Performance of Educational Buildings in Egypt, in Architecture. 2002 (Unpublished), Ain Shams University - Egypt: Cairo.

29. Humphreys, M.A., H.B. Rijal, and J.F. Nicol, Updating the adaptive relation between climate and comfort indoors; new insights and an extended database Building and Environment, 2013. 63: p. 40-55. 
30. Humphreys, M.A., Thermal comfort temperatures world-wide - the current position. Renewable Energy, 1996. 8(1-4): p. 139-144.

31. Givoni, B., Climate Consideration's in building and urban design 1998, New York: John Wiley \& Sons.

32. Centre, H.a.B.N.R., The Egyptian Specifications for Thermal Insulation Work Items, in 176/1998, U.a.U.D.E. Ministry of Housing, Editor. 2007: Cairo - Egypt.

33. Mahdy, M. and M. Nikolopoulou, The cost of achieving thermal comfort via altering external walls specifications in Egypt; from construction to operation through different climate change scenarios, in Building Simulation conference 2013: France.

34. USDoE, U.S.D.o.E.-. Weather data. 2012 [cited; Available from: http://apps1.eere.energy.gov/buildings/energyplus/weatherdata_about.cfm.

35. Group, S.E.R. Climate Change World Weather File Generator. 2012 [cited; Available from: http://www.serg.soton.ac.uk/ccworldweathergen/.

36. H Du, C.U.a.J.E., Generating design reference years from the UKCP09 projections and their application to future air-conditioning loads. Building Services Engineering Research and Technology, 2012. 33(1): p. 6379.

37. Group, S.E.R. Climate Change World Weather File Generator manual (V 1.6). 2012 [cited 1; Available from: http://www.energy.soton.ac.uk/ccworldweathergen/.

38. DB, D.S.L.-. DesignBuilder Printable Documentation v3.0. Retrieved from: http://www.designbuilder.co.uk/component/option,com_docman/task,cat_view/gid,20/Itemid,30/. 2011: Stroud, Gloucs, UK.

39. Attia, S., A. Evrard, and E. Gratia, Development of benchmark models for the Egyptian residential buildings sector. Applied Energy, 2012. 94(0): p. 270-284.

40. Mahdy, M. and M. Nikolopoulou, From construction to operation: Achieving indoor thermal comfort via altering external walls specifications in Egypt in International Conference on Green Buildings Technologies and Materials (GBTM). 2012: China.

41. EAAF, E.A.o.t.A.F.-. Indicative Guide 2012, Engineering Authority of the Armed Forces: Cairo, Egypt.

42. MOEE, M.o.E.a.E.-E.-. Egyptian Ministry of Electricity and Energy, electricity selling prices. 2012 [cited; Available from:http://www.egyptera.com/ar/a-Bill_Tariffs.htm.

43. Crawley, D.B., Impact of climate change on buildings, in Conference on Sustainable Building South-East Asia (SBO7SEA). 2007: Kuala Lumpur, Malaysia.

44. NBE, N.B.o.E.-. Interest rates. 2012 [cited; Available from: http://www.nbe.com.eg/. 


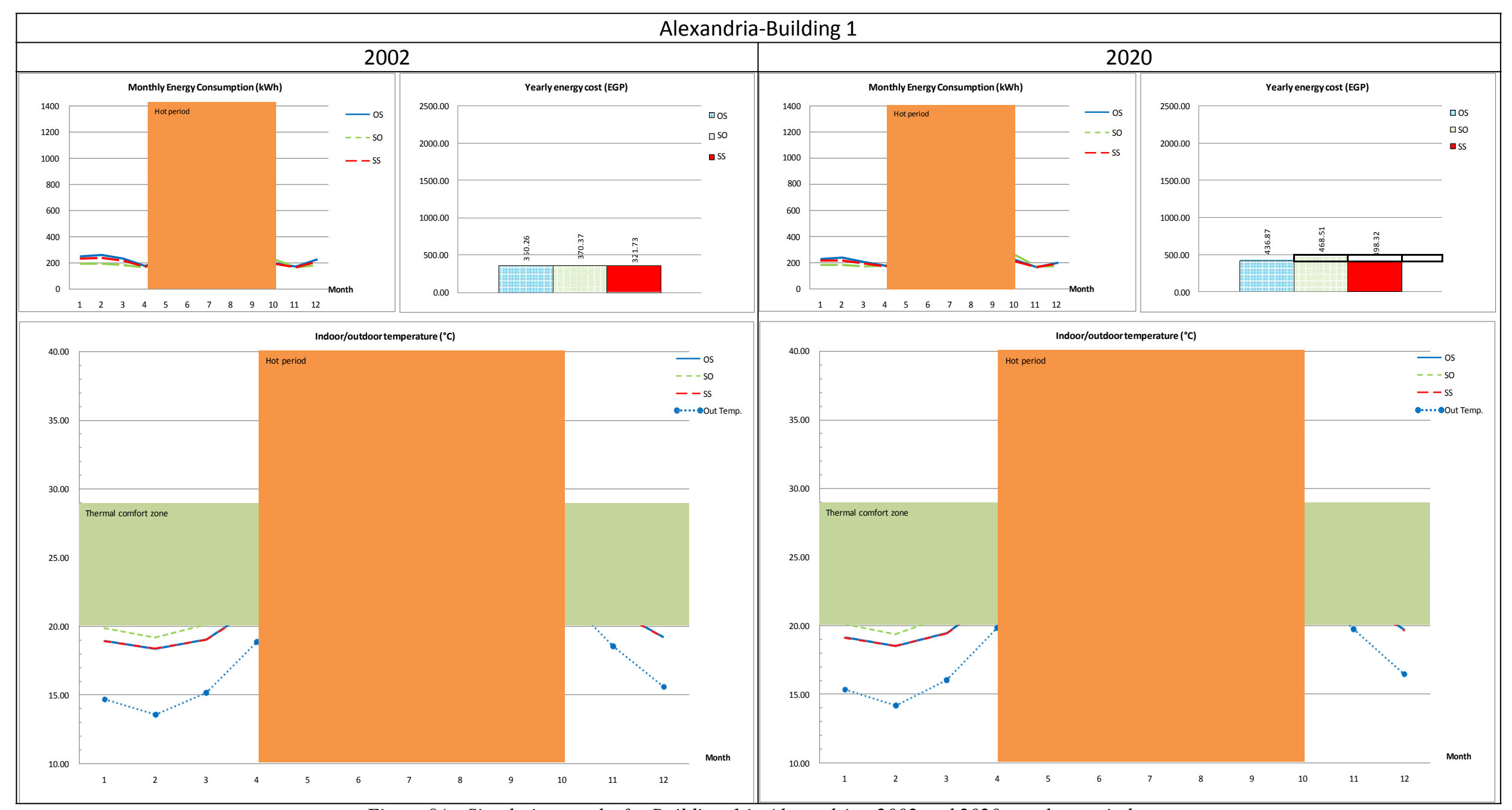

Figure 9/a: Simulation results for Building-1 in Alexandria - 2002 and 2020 weather periods. 


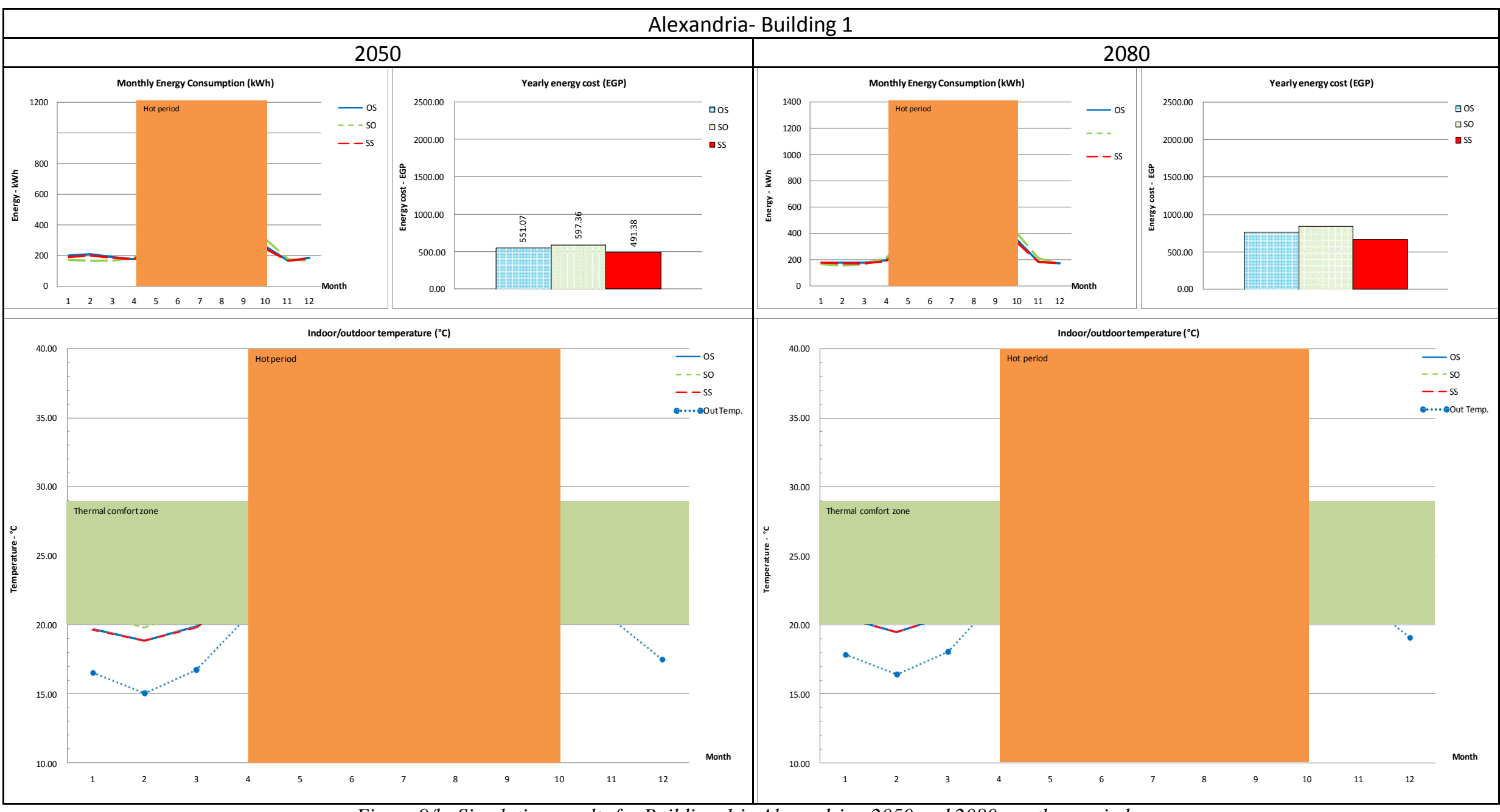

Figure 9/b: Simulation results for Building-1 in Alexandria - 2050 and 2080 weather periods. 


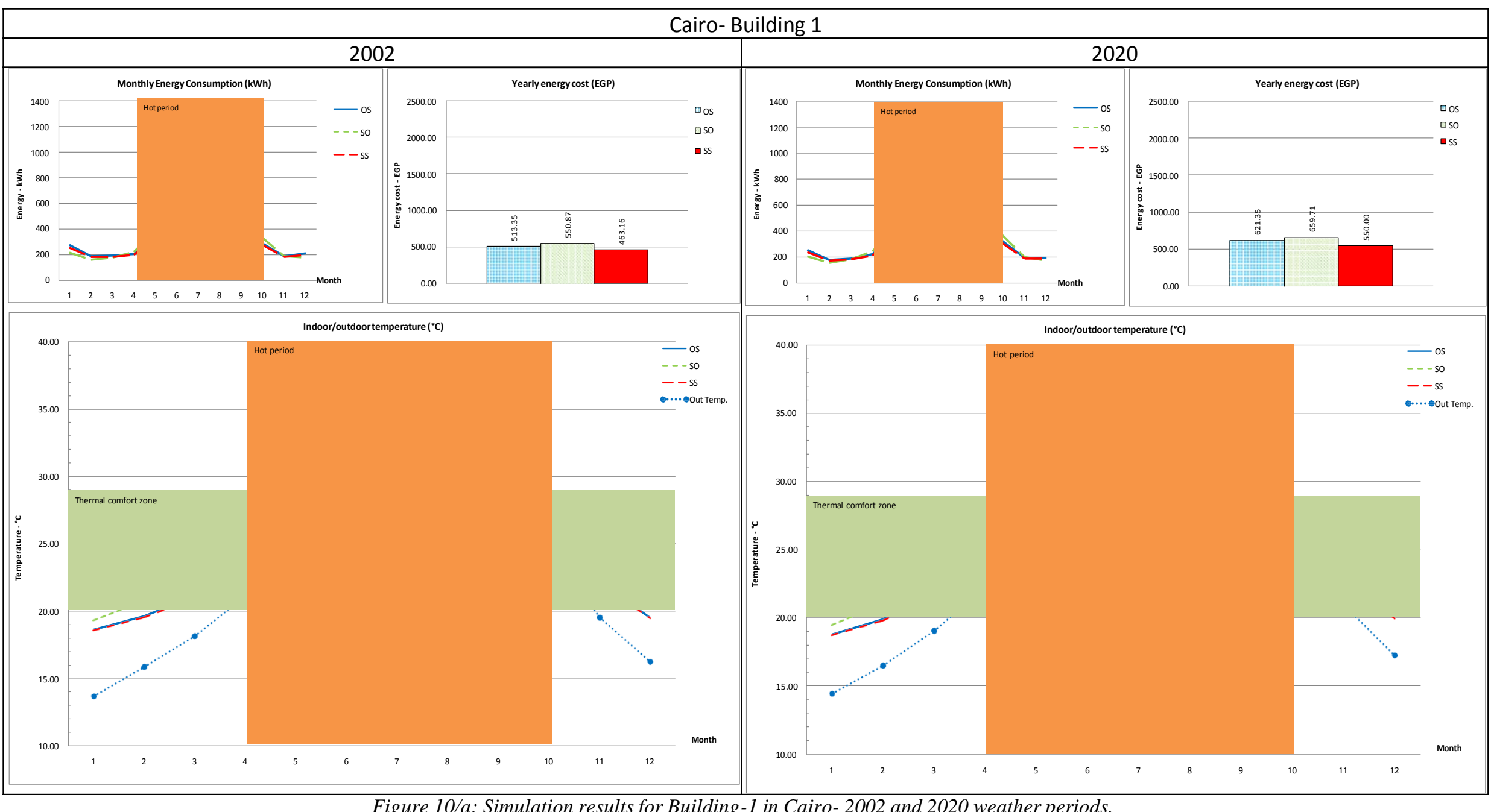

Figure 10/a: Simulation results for Building-1 in Cairo- 2002 and 2020 weather periods. 


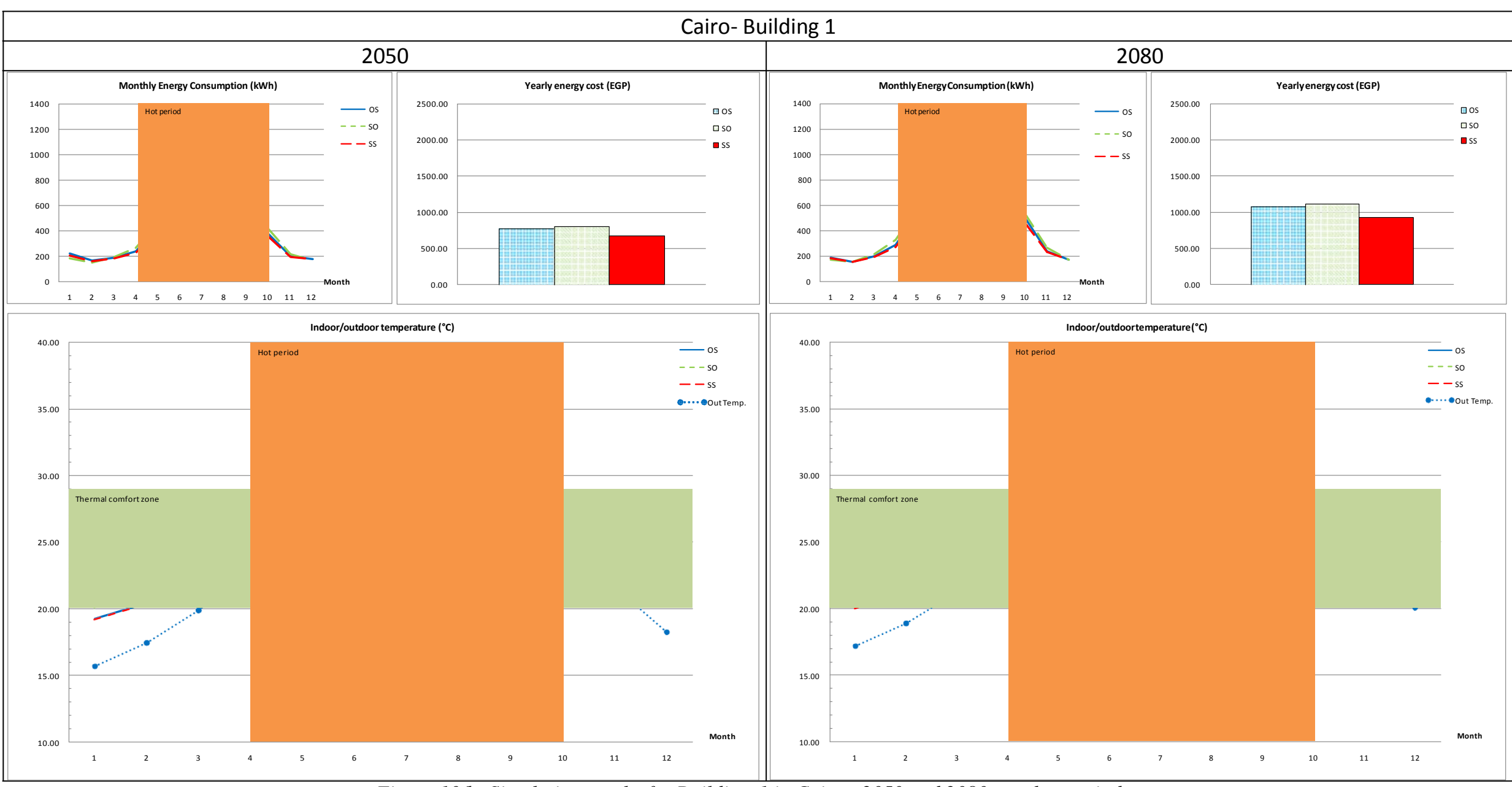

Figure 10/b: Simulation results for Building-1 in Cairo - 2050 and 2080 weather periods. 


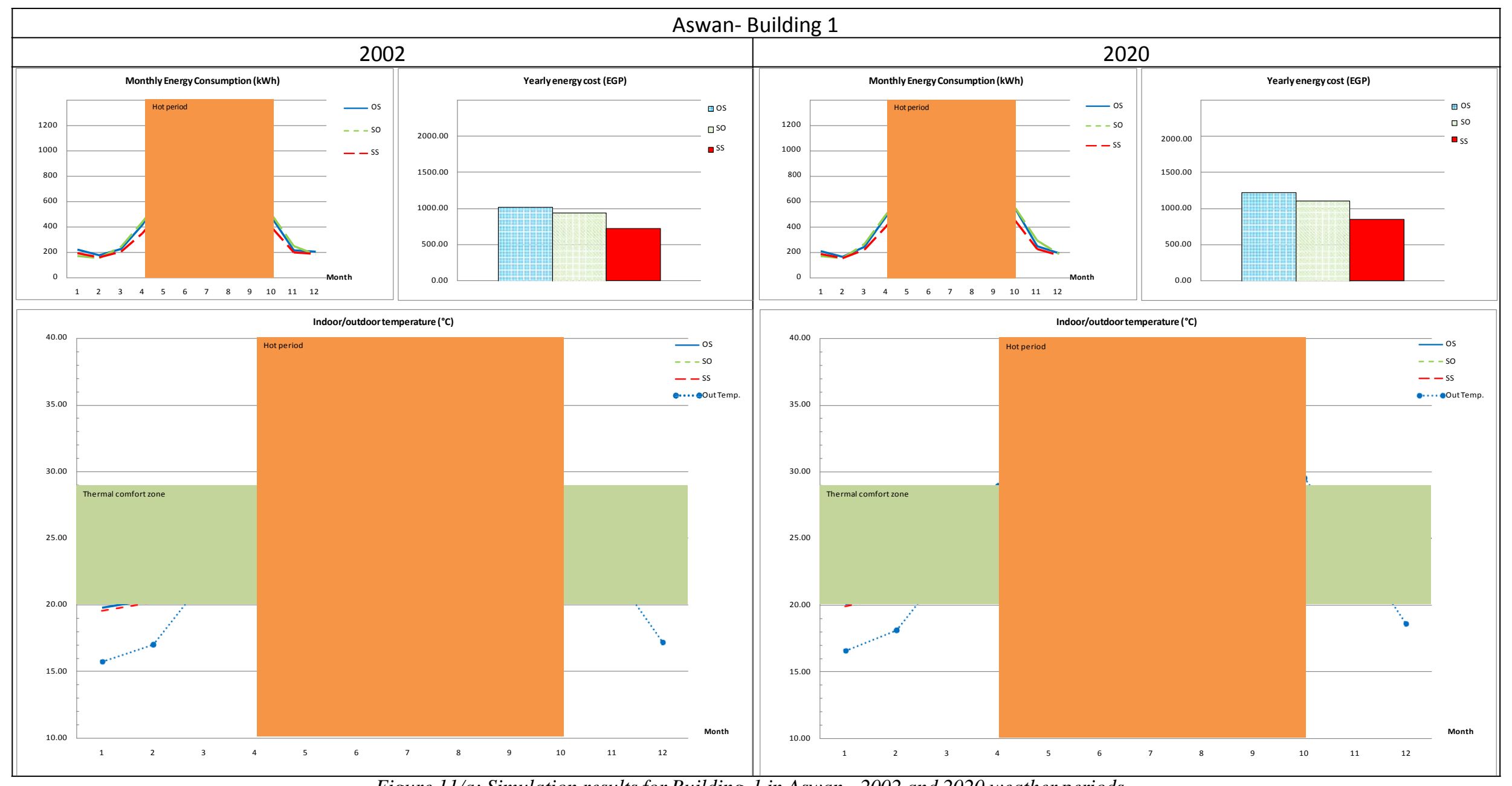

Figure 11/a: Simulation results for Building-1 in Aswan - 2002 and 2020 weather periods. 


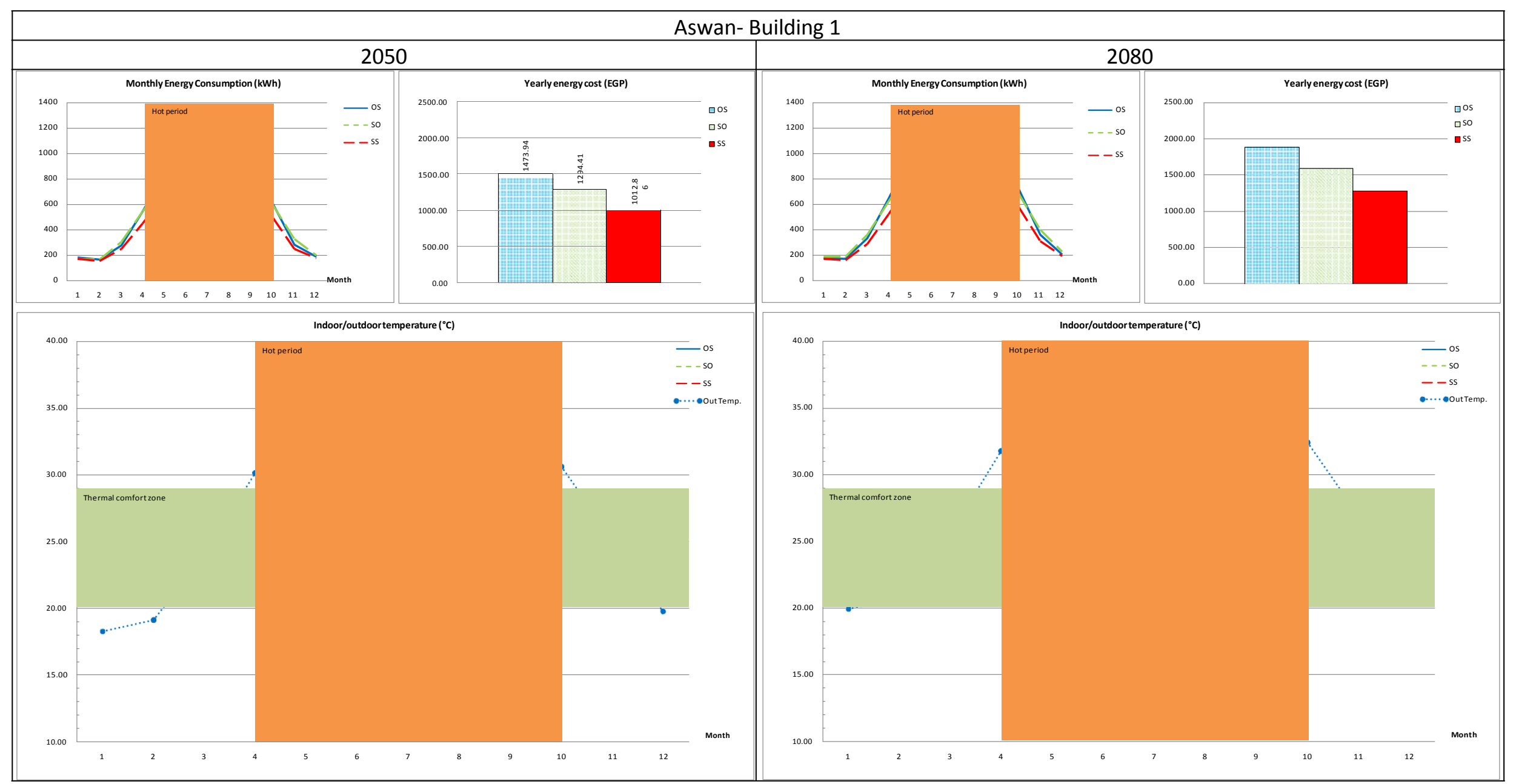

Figure 11/b: Simulation results for Building-1 in Aswan - 2050 and 2080 weather periods. 


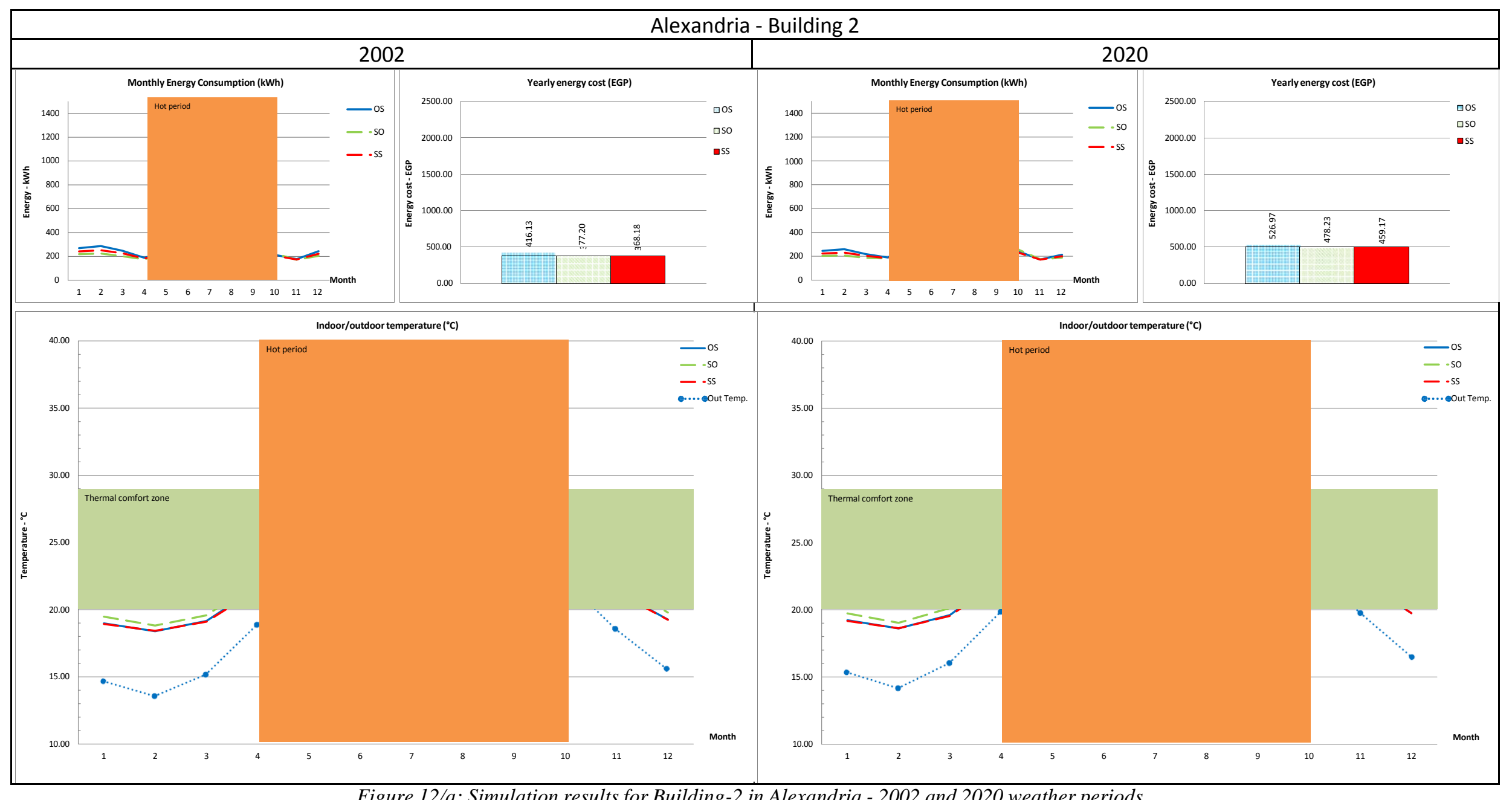

Figure 12/a: Simulation results for Building-2 in Alexandria - 2002 and 2020 weather periods. 
Alexandria - Building 2

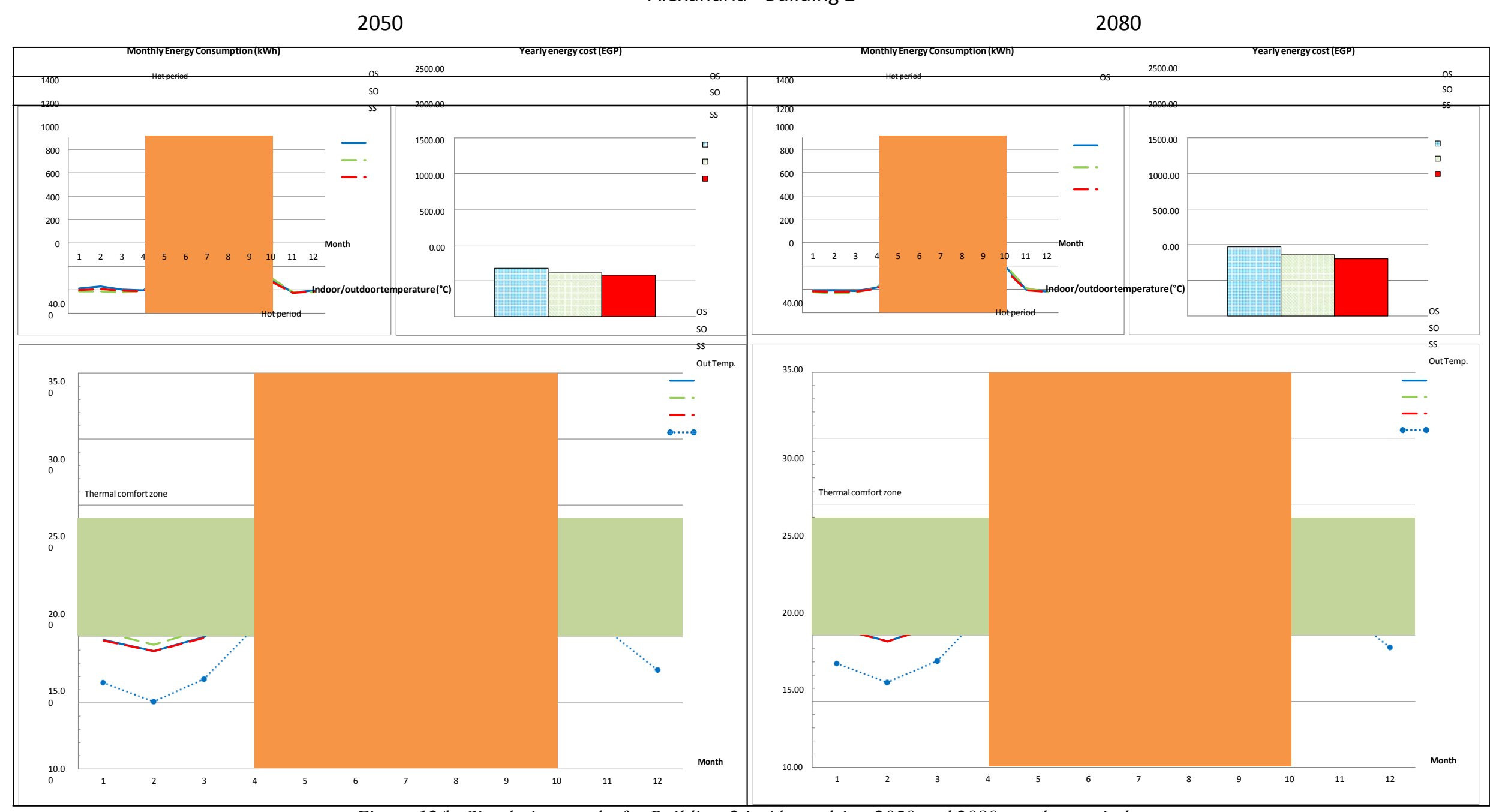

Figure 12/b: Simulation results for Building-2 in Alexandria - 2050 and 2080 weather periods. 


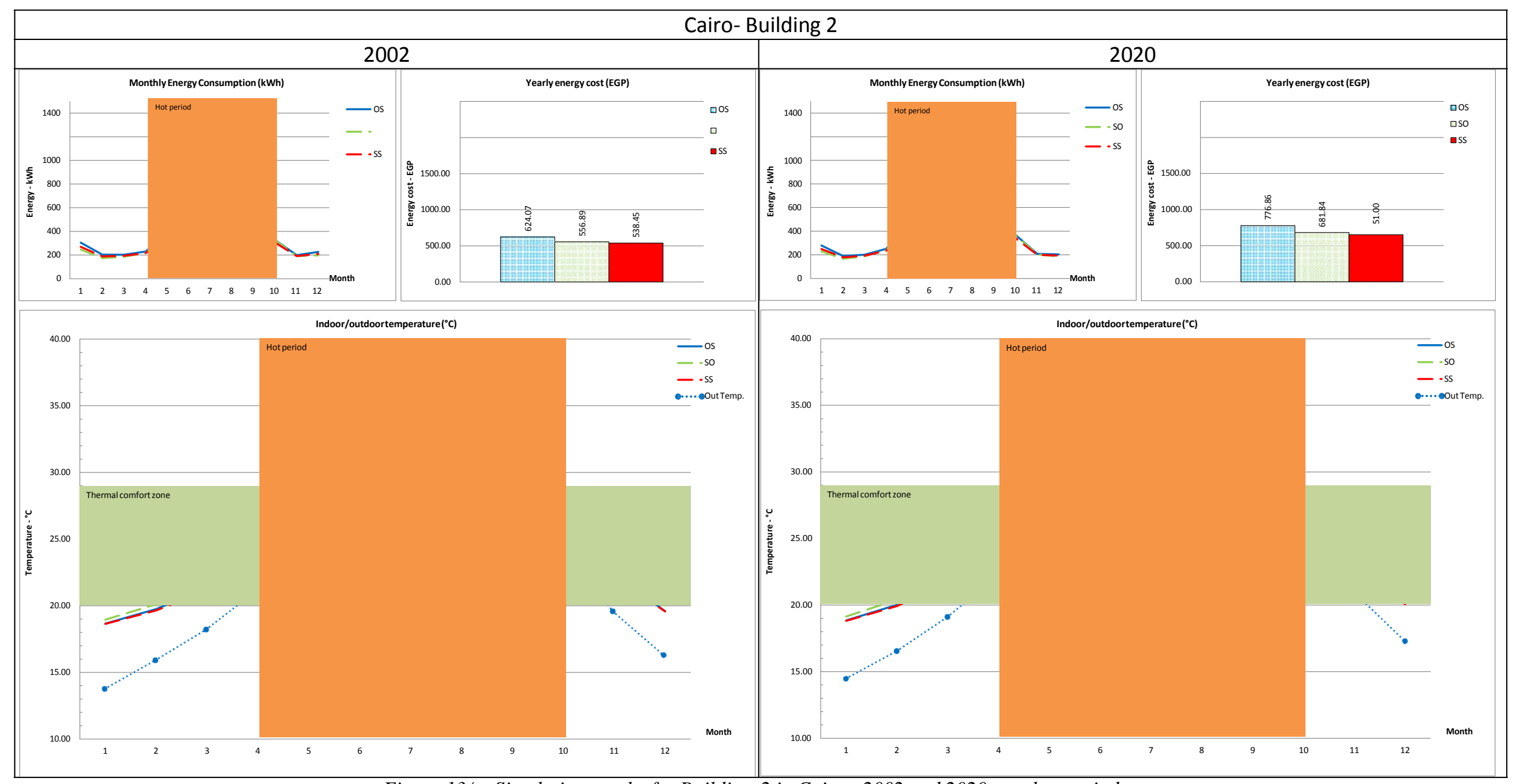

Figure 13/a: Simulation results for Building-2 in Cairo - 2002 and 2020 weather periods. 
Cairo- Building 2

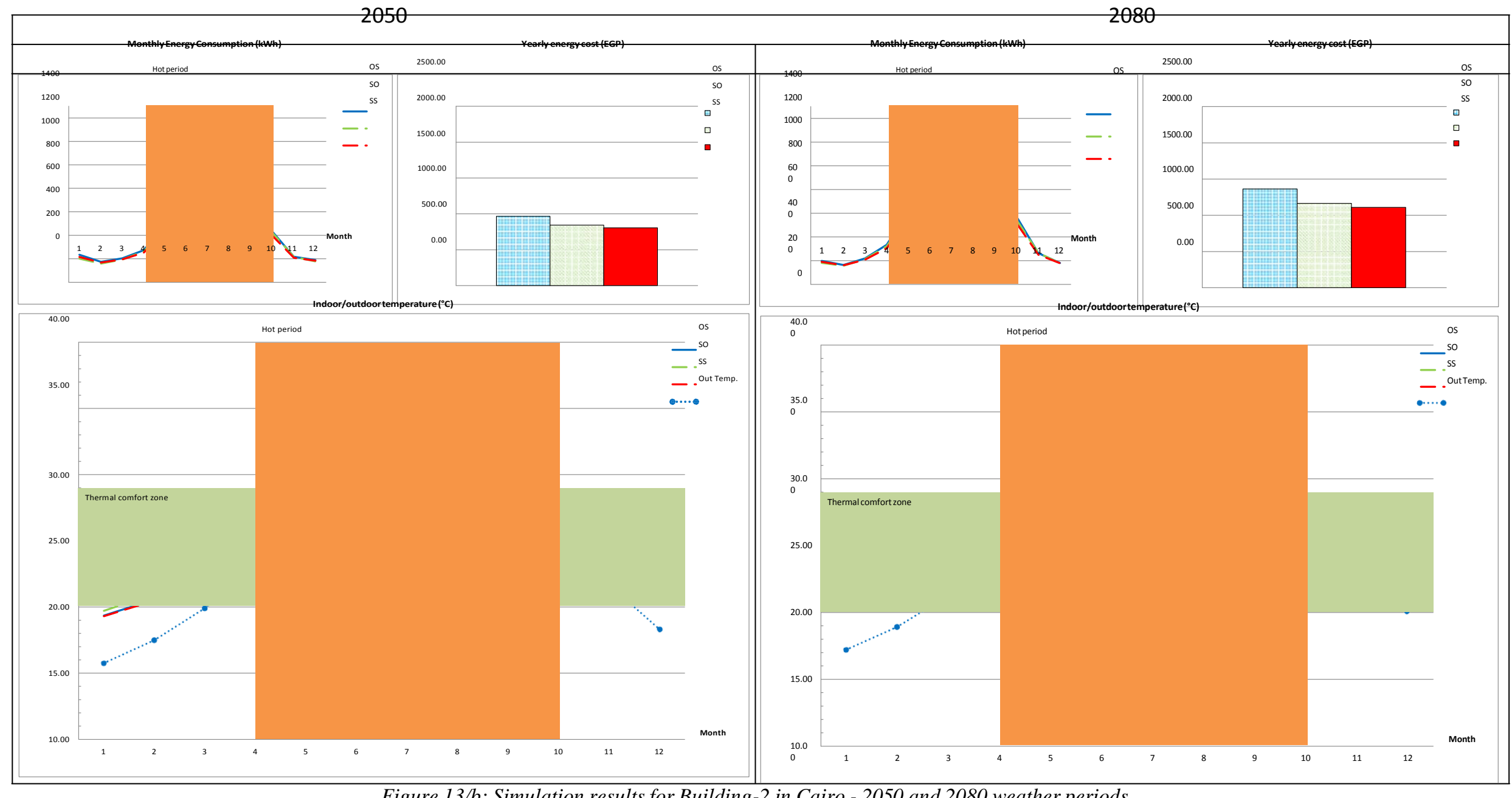

Figure 13/b: Simulation results for Building-2 in Cairo - 2050 and 2080 weather periods. 


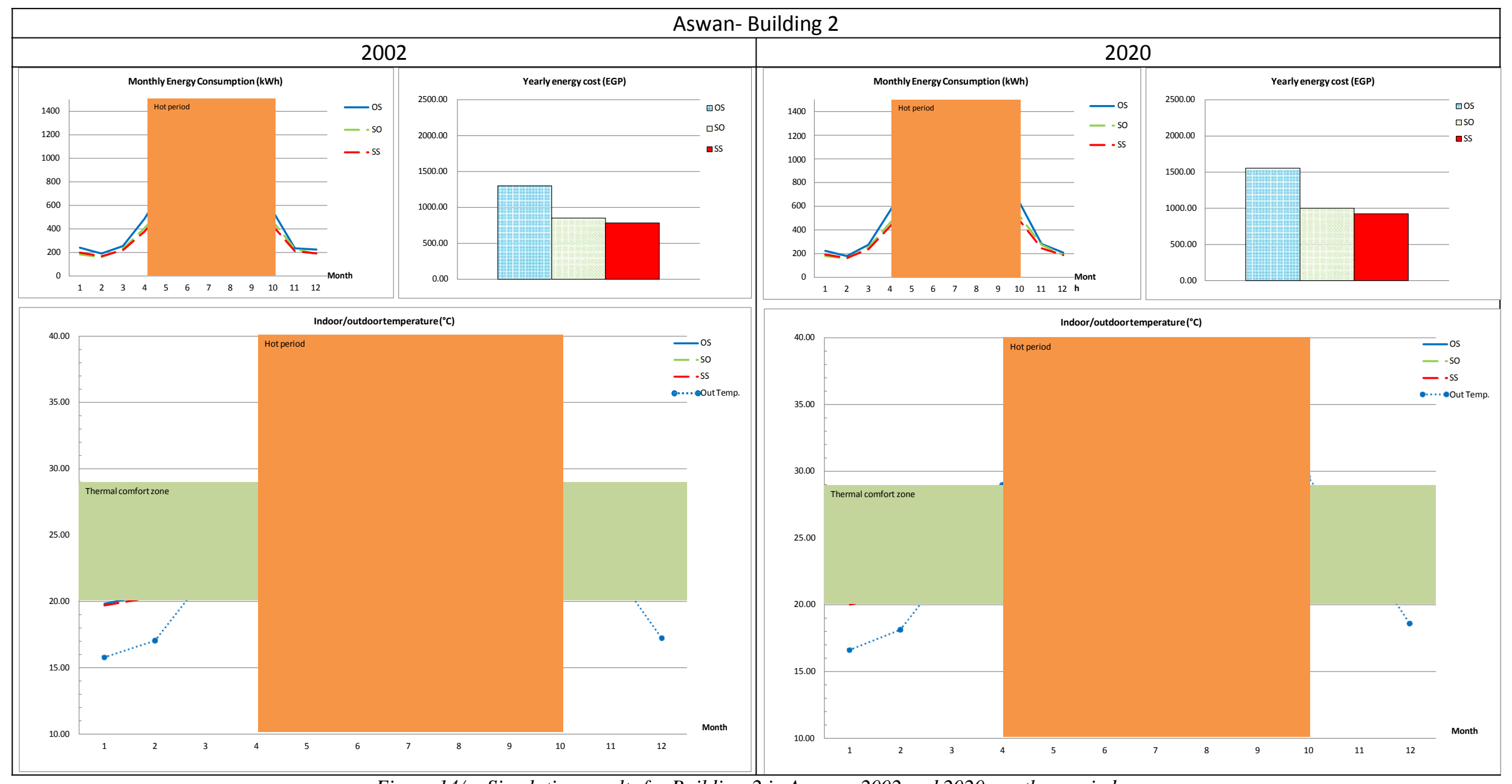

Figure 14/a: Simulation results for Building-2 in Aswan - 2002 and 2020 weather periods. 


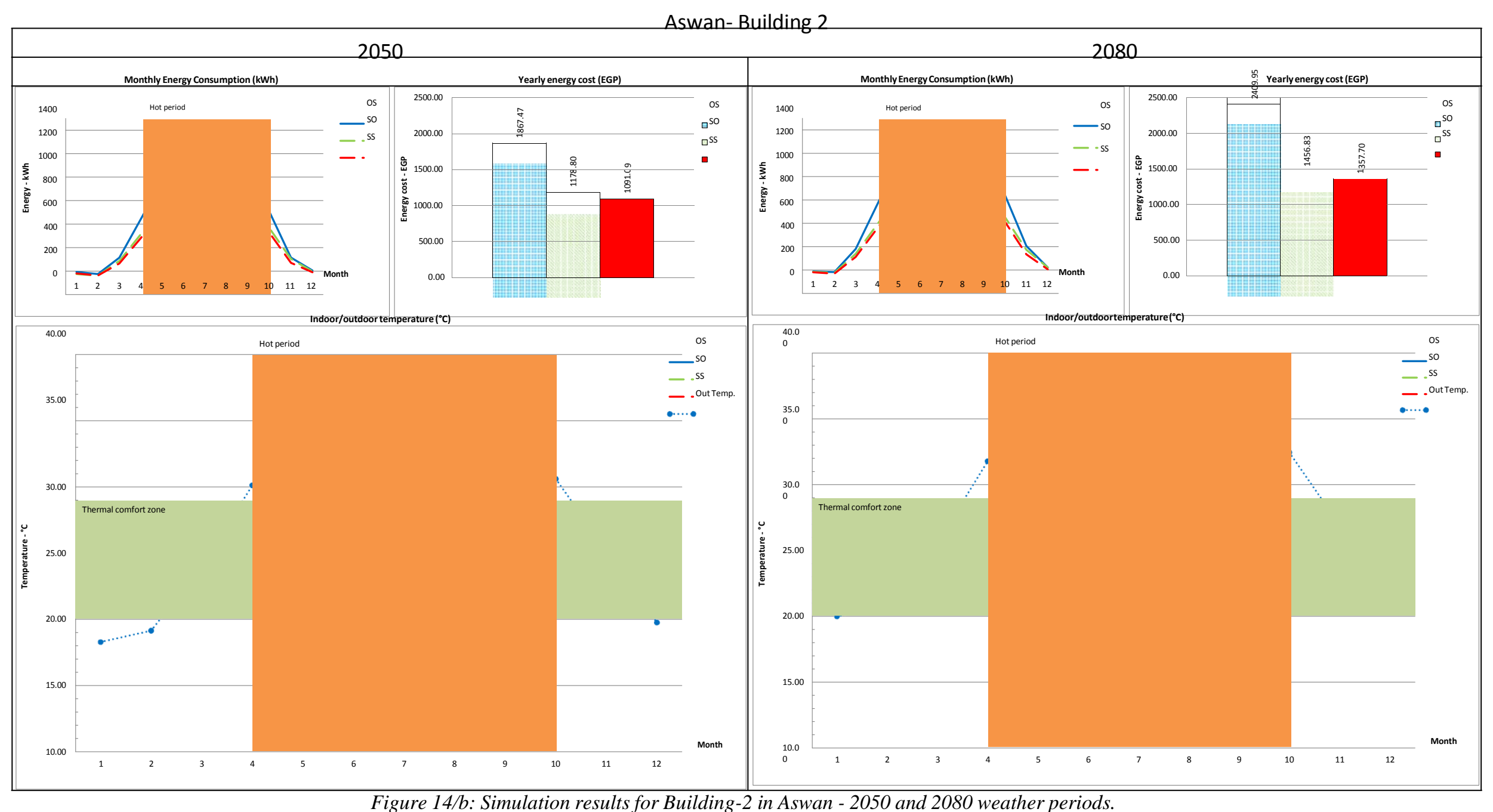


Table 6: Financial analysis for building B-1

\begin{tabular}{|c|c|c|c|c|c|c|c|c|c|c|c|c|c|c|c|c|c|c|}
\hline \multicolumn{3}{|c|}{ Alexandria } & \multirow{2}{*}{\multicolumn{2}{|c|}{$\frac{2002}{2012-2025 \text { (14 years) }}$}} & \multirow{2}{*}{\multicolumn{2}{|c|}{$\frac{2020}{2026-2039 \text { (14 years) }}$}} & \multirow{2}{*}{\multicolumn{2}{|c|}{$\frac{2050}{2040-2069 \text { (30 years) }}$}} & \multirow{2}{*}{\multicolumn{2}{|c|}{$\frac{2080}{2070-2099 \text { (30 years) }}$}} & & & \multirow[b]{2}{*}{$9 \%$} & \multirow[b]{2}{*}{88.00} & \multirow[b]{3}{*}{ diff in running costs } & \multirow[b]{3}{*}{ accumulation after 88 yrs } & & \\
\hline & & & & & & & & & & & Overall annual & Average annual running cost & & & & & & \\
\hline 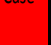 & 等 & . & Running cost & Subtotal & Running cost & Sub total & Running cost & Sub total & Running cost & Sub total & running cost & (Overall/88) & diff in initial cost & accumulation after 88 yrs & & & \multirow{2}{*}{\multicolumn{2}{|c|}{$\begin{array}{l}\text { saving in initial cost vs. saving in } \\
\text { running cost }\end{array}$}} \\
\hline sS & \multirow{3}{*}{$20 \%$} & 6635 & 321.73 & 4504.15833 & 398.32 & 5576.4366 & 491.38 & 14741.496 & 669.50 & 20084.8614 & 44906.95 & 510.31 & 0 & 0.00 & 0.00 & 0.00 & & \\
\hline os & & 5059 & 350.26 & 4903.65889 & 436.87 & 6116.17615 & 551.07 & 16532.147 & 773.85 & 23215.6438 & 50767.63 & 576.90 & $1,576.00$ & $2,842,245.15$ & 66.60 & $1,453,895.47$ & $-1,388,349.68$ & SS under OS \\
\hline so & & 6962 & 370.37 & 5185.20578 & 468.51 & 6559.15428 & 597.36 & 17920.941 & 843.66 & 25309.886 & 54975.19 & 624.72 & 327.00 & $589,729.80$ & 114.41 & 2,497,692.51 & $3,087,422.31$ & SS over SO \\
\hline
\end{tabular}

\begin{tabular}{|c|c|c|c|c|c|c|c|c|c|c|c|c|c|c|c|c|c|c|}
\hline & \multirow{3}{*}{\multicolumn{2}{|c|}{$\begin{array}{c}2002 \\
2012-2025 \text { (14 years) }\end{array}$}} & \multirow{3}{*}{\multicolumn{2}{|c|}{2020}} & \multirow{3}{*}{\multicolumn{2}{|c|}{2050}} & \multirow{3}{*}{\multicolumn{2}{|c|}{2080}} & \multirow{3}{*}{\multicolumn{2}{|c|}{\begin{tabular}{|l|l|}
\multicolumn{2}{|c|}{} \\
Overall annual & Average annual runing cost \\
\end{tabular}}} & \multirow[b]{3}{*}{$9 \%$} & \multirow{3}{*}{88.00} & & & \\
\hline & & & & & & & & & & & & & & & & & & \\
\hline \multirow{2}{*}{ Case } & \multirow{2}{*}{ WWR } & \multirow{2}{*}{ |nitial cost } & & & & & & & & & & & & & & & & \\
\hline & & & Running cost & Sub total & Running cost & Sub total & Running cost & Sub total & Running cost & Sub total & running cost & (Overall//88) & diff in intial cost & accumulation after 88 yrs & diff in running costs & accumulation after 88 yrs & \multirow{2}{*}{\multicolumn{2}{|c|}{$\begin{array}{l}\text { saving in intitial cost vs. saving in } \\
\text { running cost (EGP) }\end{array}$}} \\
\hline SS & \multirow{3}{*}{$20 \%$} & 6635 & 463.16 & 6484.27918 & 550.00 & 7700.01947 & 676.49 & 20294.589 & 930.35 & 27910.6491 & 62389.54 & 708.97 & 0 & 0.00 & 0.00 & 0.00 & & \\
\hline OS & & 5059 & 513.35 & 7186.85309 & 621.35 & 8698.95146 & 774.73 & 23241.838 & 1082.21 & 32466.3923 & 71594.03 & 813.57 & $1,576.00$ & $2,842,245.15$ & 104.60 & $2,283,419.69$ & $.558,825.46$ & SS under OS \\
\hline SO & & 7117 & 550.87 & 7712,19179 & 659.71 & 9235.87695 & 813.31 & 24399.199 & 1115.78 & 33473.4477 & 74820.72 & 850.24 & 482.00 & $869,265,33$ & 141.26 & $3,083,883,32$ & $3,953,148,65$ & SS over SO \\
\hline
\end{tabular}

Aswan

\begin{tabular}{|c|c|c|c|c|c|c|c|c|c|c|c|c|c|c|c|c|c|c|}
\hline \multirow{2}{*}{\multicolumn{3}{|c|}{ Aswan }} & \multirow{3}{*}{\multicolumn{2}{|c|}{$\begin{array}{c}2002 \\
2012-2025 \text { (14years) }\end{array}$}} & \multirow{3}{*}{\multicolumn{2}{|c|}{$\begin{array}{c}2020 \\
2026-2039 \text { (14years) }\end{array}$}} & \multirow{3}{*}{\multicolumn{2}{|c|}{$\frac{2050}{2040-2069 \text { (30years) }}$}} & \multirow{2}{*}{\multicolumn{2}{|c|}{2080}} & & & \multirow{3}{*}{\multicolumn{2}{|c|}{88.00}} & & & & \\
\hline & & & & & & & & & & & \multirow{3}{*}{$\begin{array}{l}\text { Overall annual } \\
\text { running cost }\end{array}$} & \multirow{3}{*}{$\begin{array}{c}\text { Average annual running cost } \\
\text { (Overall/88) }\end{array}$} & & & \multirow[b]{3}{*}{ diffin running costs } & \multirow[b]{3}{*}{ accumulation after 88yrs } & & \\
\hline \multirow{2}{*}{ Case } & \multirow{2}{*}{ WWR } & \multirow{2}{*}{$\begin{array}{l}\text { Intitial } \\
\text { cost }\end{array}$} & & & & & & & $2070-2099 / 3$ & 30years) & & & & & & & & \\
\hline & & & Running cost & Subtotal & Running cost & Subtotal & Running cost & Subtotal & Runningcost & Subtotal & & & diffininitial cost & accumulation after 88yrs & & & \multirow{2}{*}{\multicolumn{2}{|c|}{$\begin{array}{l}\text { saving in initial costvs. saving in } \\
\text { running cost(EGP) }\end{array}$}} \\
\hline SS & \multirow{3}{*}{$20 \%$} & 9500 & 722.96 & 10121.3848 & 853.92 & 11954.9368 & 1012.86 & 30385.654 & 1280.02 & 38400.6848 & 90862.66 & 1032.53 & 0 & 0.00 & 0.00 & 0.00 & & \\
\hline OS & & 5059 & 1021.49 & 14300.8264 & 1225.90 & 17162.6214 & 1473.94 & 44218.34 & 1894.51 & 56835.4007 & 132517.19 & 1505.88 & $4,441.00$ & $8,009,143.85$ & 473.35 & 10,333,510.15 & $2,324,366.30$ & G1 under G2 \\
\hline so & & 10033 & 949.01 & $|13286.1628|$ & 1109.10 & $|15527.3926|$ & 1294.41 & 38832.44 & 1601.37 & 48041.1671 & 115687.16 & 1314.63 & 533.00 & $961,241.54$ & 282.10 & $6,158,375.97$ & $7,119,617.50$ & G1 over G3 \\
\hline
\end{tabular}


Table 7: Financial analysis for building B-2

\begin{tabular}{|c|c|c|c|c|c|c|c|c|c|c|c|c|c|c|c|c|c|c|}
\hline \multirow{2}{*}{\multicolumn{3}{|c|}{ Alexandria }} & \multirow{3}{*}{\multicolumn{2}{|c|}{$\begin{array}{c}2002 \\
2012-2025 \text { (14 years) }\end{array}$}} & \multirow{3}{*}{\multicolumn{2}{|c|}{$\begin{array}{c}2020 \\
2026-2039 \text { (14 years) }\end{array}$}} & & & \multirow{3}{*}{\multicolumn{2}{|c|}{$\begin{array}{c}2080 \\
2070-2099 \text { (30 years) }\end{array}$}} & \multirow{4}{*}{$\begin{array}{l}\text { Overall annual } \\
\text { running cost }\end{array}$} & \multirow{4}{*}{$\begin{array}{l}\text { Average annual running } \\
\text { cost (Overall/88) }\end{array}$} & \multirow[b]{3}{*}{$9 \%$} & \multirow[b]{3}{*}{88.00} & & & & \\
\hline & & & & & & & \multirow{2}{*}{\multicolumn{2}{|c|}{$\begin{array}{c}2050 \\
2040-2069 \text { (30 years) }\end{array}$}} & & & & & & & & & & \\
\hline \multirow{2}{*}{ Case } & \multirow{2}{*}{ WWR } & \multirow{2}{*}{$\begin{array}{l}\text { Initial } \\
\text { cost }\end{array}$} & & & & & & & & & & & & & & & & \\
\hline & & & Running cost & Sub total & Running cost & Sub total & Running cost & Sub total & Running cost & Sub total & & & diff in initial cost & accumulation after $88 \mathrm{yrs}$ & diff in running costs & accumulation after 88 yrs & \multirow{2}{*}{\multicolumn{2}{|c|}{$\begin{array}{l}\text { saving in initial cost vs. saving in } \\
\text { running cost }\end{array}$}} \\
\hline sS & \multirow{3}{*}{$20 \%$} & 7467 & 368.18 & 5154.562 & 459.17 & 6428.40785 & 578.02 & 17340.676 & 802.82 & 24084.5239 & 53008.17 & 602.37 & 0 & 0.00 & 0.00 & 0.00 & & \\
\hline os & & 5578 & 416.13 & 5825.8373 & 526.97 & 7377.63618 & 676.00 & 20279.988 & 968.13 & 29043.9702 & 62527.43 & 710.54 & $1,889.00$ & $3,406,726.58$ & 108.17 & $2,361,505.34$ & $-1,045,221.24$ & SS under OS \\
\hline so & & 7316 & 377.20 & 5280.75166 & 478.23 & 6695.15948 & 610.29 & 18308.608 & 856.56 & 25696.8981 & 55981.42 & 636.15 & 151.00 & $272,321.71$ & 33.79 & $737,592.89$ & $465,271.18$ & SS over SO \\
\hline
\end{tabular}

\begin{tabular}{|c|c|c|c|c|c|c|c|c|c|c|c|c|c|c|c|c|c|c|}
\hline \multicolumn{3}{|c|}{ Cairo } & \multirow{2}{*}{\multicolumn{2}{|c|}{$\frac{2002}{2012-2025 \text { (14 years) }}$}} & \multirow{2}{*}{\multicolumn{2}{|c|}{$\frac{2020}{2026-2039 \text { (14 years) }}$}} & \multirow{2}{*}{\multicolumn{2}{|c|}{$\frac{2050}{2040-2069 \text { (30 years) }}$}} & \multirow{2}{*}{\multicolumn{2}{|c|}{$\frac{2080}{2070-2099 \text { (30 years) }}$}} & \multirow{3}{*}{$\begin{array}{l}\text { Overall annual } \\
\text { running cost }\end{array}$} & \multirow{3}{*}{$\begin{array}{c}\text { Average annual running cost } \\
\text { (Overall/88) }\end{array}$} & \multirow{2}{*}{\multicolumn{2}{|c|}{88.00}} & & & & \\
\hline & & Wrat & & & & & & & & & & & & & & & & \\
\hline & & & Running cost & Sub total & Running cost & Sub total & Running cost & Subtotal & Running cost & Sub total & & & diff in initial cost & accumulation after 88 yrs & diff in running costs & accumulation after 88 yrs & \multirow{2}{*}{\multicolumn{2}{|c|}{$\begin{array}{l}\text { saving in initial cost vs. saving in } \\
\text { running cost }\end{array}$}} \\
\hline ss & \multirow{3}{*}{$20 \%$} & 7467 & 538.45 & 7538.29126 & 651.00 & 9114.06295 & 805.24 & 24157.052 & 1110.12 & 33303.5451 & 74112.95 & 842.19 & 0 & 0.00 & 0.00 & 0.00 & & \\
\hline os & & 5578 & 624.07 & 8737.03997 & 776.86 & 10876.0262 & 965.00 & 28949.858 & 1362.70 & 40881.1348 & 89444.06 & 1016.41 & $1,889.00$ & $3,406,726.58$ & 174.22 & $3,803,287.60$ & $396,561.02$ & SS under OS \\
\hline so & & 7477 & 556.89 & |7796.47295 & 681.84 & 9545.71414 & 841.90 & 25256.883 & 1163.29 & 34898.5702 & 77497.64 & 880.66 & 10.00 & $18,034.55$ & 38.46 & $839,661.78$ & $857,696.33$ & SS over SO \\
\hline
\end{tabular}

\begin{tabular}{|c|c|c|c|c|c|c|c|c|c|c|c|c|c|c|c|c|c|c|}
\hline \multicolumn{3}{|c|}{ Aswan } & \multirow{2}{*}{\multicolumn{2}{|c|}{$\frac{2002}{2012-2025 \text { (14 years) }}$}} & \multirow{2}{*}{\multicolumn{2}{|c|}{$\frac{2020}{2026-2039 \text { (11 years) }}$}} & \multirow{2}{*}{\multicolumn{2}{|c|}{$\frac{2050}{2040-2069 \text { (30 years) }}$}} & \multirow{2}{*}{\multicolumn{2}{|c|}{$\frac{2080}{2070-2099 \text { (30 years) }}$}} & \multirow{3}{*}{$\begin{array}{l}\text { Overall annual } \\
\text { running cost }\end{array}$} & \multirow{3}{*}{$\begin{array}{c}\text { Average annual running cost } \\
\text { (Overall/88) }\end{array}$} & \multirow{2}{*}{\multicolumn{2}{|c|}{88.00}} & \multirow[b]{3}{*}{ diff in running costs } & \multirow[b]{3}{*}{ accumulation after 88 yrs } & & \\
\hline & & & & & & & & & & & & & & & & & & \\
\hline & whin & tiviat & Running cost & Sub total & Running cost & Sub total & Running cost & Sub total & Running cost & Sub total & & & diff in intital cost & accumulation after 88 yrs & & & \multirow{2}{*}{\multicolumn{2}{|c|}{$\begin{array}{l}\text { saving in initial cost vs. saving in } \\
\text { running cost }\end{array}$}} \\
\hline SS & \multirow{3}{*}{$20 \%$} & 10902 & 785.97 & 11003.5177 & 923.74 & 12932.3098 & 1091.09 & 32732.791 & 1357.70 & 40731.0421 & 97399.66 & 1106.81 & 0 & 0.00 & 0.00 & 0.00 & & \\
\hline OS & & 5578 & 1300.39 & 18205.462 & 1553.70 & 21751.8061 & 1867.47 & 56024.029 & 2409.95 & 72298.5655 & 168279.86 & 1912.27 & $5,324.00$ & $9,601,594.65$ & 805.46 & $17,583,713.54$ & $7,982,118.88$ & SS over OS \\
\hline so & & 10912 & 851.19 & 11916.6287 & 1000.52 & 14007.2173 & 1178.80 & 35364.029 & 1456.83 & 43705.0315 & 104992.91 & 1193.10 & 10.00 & $18,034.55$ & 86.29 & $1,883,706.03$ & $1,901,740.58$ & SS over so \\
\hline
\end{tabular}

